\title{
FROM GAS RELEASE TO FOAM SYNTHESIS, THE SECOND BREATH OF BLOWING AGENTS
}

\author{
Guilhem Coste $^{1}$, Claire Negrell ${ }^{1}$, Sylvain Caillol ${ }^{1^{*}}$ \\ ${ }^{1}$ ICGM, Univ Montpellier, CNRS, ENSCM, Montpellier, France \\ Corresponding author: Sylvain Caillol - sylvain.caillol@enscm.fr
}

Keywords: chemical blowing agent; foam; foaming process; polymer

\begin{abstract}
:
The increasing concern about the environmental impact of physical blowing agents (PBAs) favours the use of chemical blowing agents (CBAs) to replace controversial PBAs. Blowing agents are key compounds in order to obtain polymer foams. Indeed, blowing agents are crucial additives that release gas needed to blow polymer foams. CBA compounds have been widely studied in recent decades, and today if new CBA are studied, one of the challenges remains to adapt the use of CBA to new polymers or new formulations. Only a handful of books present different CBAs commercially available but in these documents, the presentation of CBAs is not enough complete to understand potential or limits. Thus, our work is focused on the most common, both inorganic and organic chemical blowing agents and highlights the specifications of these CBAs, with their advantages and drawbacks, and finally presents promising perspectives.
\end{abstract}

\section{Introduction}

Polymer foams are diphasic thermosets, composed of both a solid and a gas phase. They are widely used in everyday life due to their lightness, reduced thermal conductivity, high-energy absorption, and excellent strength/weight ratio. These foams are used is a huge variety of applications such as transportation, bedding, textile, toys, sport instruments, insulation appliances, and construction, biomedical, and automotive sectors. ${ }^{1}$ Polymer foams can be either rigid or flexible with different cell geometry such as open or closed cell. They can be processed from various polymers such as polyurethane (PU), polystyrene (PS), poly(vinyl chloride) (PVC), polyethylene (PE), polypropylene (PP) or poly(methyl methacrylate) $)^{2}$, etc. Plastic foams are gaining increasing importance with a global market of around $\$ 100$ billion in 2015 and more than $\$ 110$ billion in 2019. ${ }^{1}$ Foam market is expected to have a compound annual growth rate of 3.8\% between 2020 and 2027. Foam market is dominated by PU foams with a production of more than $12 \mathrm{Mt}$ in 2016, which represents two-third of total PU production. ${ }^{1,4,5} \mathrm{PU}$ are widely used due to their easy synthesis using polyols and isocyanates and their unique properties. ${ }^{6}$ Due to environmental issues, reducing fuel consumption is one of the main challenges of the present and future for our society. A solution to reduce fuel consumption is to lighten vehicles or other fuel consuming vehicles. To meet this challenge, plastics, composites and especially polymer foams are currently gaining increasing attention.

Foams are expanded materials, thus the release of gas is necessary to create cells and obtain such expanded materials of low density. Indeed foam properties are linked to their density and their 
structure: cells size, their dispersion in the polymer matrix, presence of open or close cell, etc. In order to create cells, research scientists have developed substances responsible of cell-production defined as blowing agents (BA). There are two classes of blowing agents, Physical Blowing Agents (PBAs) and Chemical Blowing Agents (CBAs). First, PBAs are mainly gases directly injected during the curing of the materials such as butane, , carbon dioxide, which expand when the pressure is reduced. ${ }^{7}$ However, PBAs can also be low boiling point liquids such as low molar mass molecules. These PBAs are mainly short aliphatic chain molecules $\left(C_{5}-C_{6}\right)$ such as pentane or various hydrofluoroolefins such as 1,3,3,3-tetrafluoropropene. On the other hand, CBAs are compounds that release gas under specific conditions, e.g. under curing conditions, in order to obtain a foam. Hence, the released gas comes either from a thermal decomposition or a chemical reaction. ${ }^{8,9}$ One of the most described reactions is the reaction between isocyanate and water. ${ }^{10}$ Additionally, CBAs are subdivided in two categories: exothermic and endothermic blowing agents.

The oldest method using PBA was developed in 1952 in order to blow rubber. In this method air was whipped mechanically into the latex. ${ }^{11}$ The method is still applied nowadays to both ureaformaldehyde resin and PVC foams. ${ }^{7}$ Then, the discovery of chlorofluorocarbons (CFCs) during the late 1950s led to an increase of PU foams production. Due to their high chemical and thermal stability and low cost, CFCs were widely used for all the PU foams. However in the early 1980s, it was proven that CFCs had a high destructive effect on the ozone layer. ${ }^{12}$ In consequence, the Montreal Protocol on the Substances that Deplete the Ozone Layer in the late 1980s organized the phase-out of CFCs compounds and other ozone-depleting substances. Hence, the Montreal Protocol has significantly influenced the foam industry. Consequently, CFCS were replaced by hydrochlorofluorocarbons (HCFCs). Indeed, HCFCs exhibit a significantly lower ozone depletion potential (ODP) than CFCs. However their global warming potential (GWP) is higher. For this reason, the Montreal Protocol in 2007 decided an accelerated phase-out of HCFCs. Consequently, the industry developed hydrofluorocarbons, fluorinated gas with zero ODP but still high GWP. Therefore the adjustment of Montreal Protocol encourages continuously industry to find alternatives. ${ }^{13}$ Several alternatives were recently found, such as the use of natural inert gas (carbon dioxide, nitrogen), hydrocarbons (HC) and lately hydrofluoroolefins (HFOs). Hence, HFOs are considered as possible substitutes due to their low GWP and zero ODP. ${ }^{14}$ However, even with these new synthetic PBAs, some independent environmental organizations keep criticize synthetic PBAs. ${ }^{15}$ Thus, the substitution of the fluorinated gas by HFOs seems not so obvious. Moreover, due to their high cost, HFOs are not so interesting from industrial point of view. Therefore, carbon dioxide remains the most used PBA nowadays due to low toxicity, high stability, and low cost. In order to obtain a foam, the compressed carbon dioxide is dissolved under high pressure in the polymer melt. The foam structure is then obtained by reducing pressure. ${ }^{2}$ Some foams are obtained using mechanical mixing to diffuse air into the liquid in order to obtain a liquid foam. These liquids foams are then cured to stabilize the foam, e.g. the work present by Szczurek et al. about tannin-based foams. ${ }^{16}$ Nowadays, supercritical carbon dioxide is also used to blow foam, e.g. Grignard et al. carried out the synthesis of a polyhydroxyurethane foam using supercritical carbon dioxide. ${ }^{17}$ Despite its low cost, this BA requires a special equipment in order to obtain a great diffusion of the BA in the polymer. Overall, PBA are widely used by foam industry but it seems that the legislation has compromised their future. Moreover they require special and costly equipment in order to work under pressure. Therefore, CBAs could be a great alternative to all these issues. 
CBAs are less used than PBA for various reasons. The first one is the expensive cost of CBAs. This cost induces a limitation toward the densities of the blown foams. Indeed for the same density, a foam blown using a CBA costs 10 times more than a foam blown using gas from a pressured cylinder. ${ }^{8}$ The second reason is the foam structure obtained using CBA. Indeed, CBAs, generally lead to small gaseous molecules such as $\mathrm{CO}_{2}, \mathrm{~N}_{2}$, or $\mathrm{H}_{2}$ that have a high diffusion rate in the polymer and lead to open cell structures. Even if open cell structures are interesting in several applications such as insulation or mattresses, the use of CBA could limit the field of applications of foam therefrom. ${ }^{18}$ Additives could be incorporated to improve the structure but it implies an increase in cost. Nevertheless, CBAs are interesting for multiple reasons. The first one is that they do not require specific equipment unlike the PBAs. Indeed, most of CBAs are solid. Thus, they are easily incorporated by direct mixing in the polymer matrix. Depending on the conditions, the CBAs directly produce gas in the material. Thus, the diffusion of the CBAs is easier to control unlike PBAs. Therefore, both the use of CBAs and the required equipment are easier. Secondly, CBAs do not involve working under high pressure because the physical state of CBAs does not change with pressure. Furthermore, CBAs allow a larger operating window, self-nucleation and thinner cells. However, some problems are linked to the use of CBAs such as the presence of residues if the CBAs are not totally degraded or due to by-products. Indeed, these residues could entail a decrease of the mechanical properties or lead to toxicity concern in case of specific migration of the residue in the material. Several CBAs are already widely used in industry in PVC foam, polyolefin or rubber foams. ${ }^{19}$ Despite the higher price and the other drawbacks of these CBAs, they are the main alternative to the PBAs. The wide variety of CBAs is interesting in order to blow different polymer foams depending on the required conditions. The main issue remains the conditions of foaming. Indeed, the required conditions depend both on CBAs degradation and on the polymerization reactivity in order to obtain a foam. The main parameter remains the temperature but it is not the only one

Despite literature reports numerous pieces of work concerning CBAs-based foams, to the best of our knowledge, there is not comparative review presenting the various CBAs and discussing the conditions of use. Hence, in this original perspective paper, we propose to consider for the first time the different parameters studied in the literature concerning Chemical Blowing Agents, from synthesis, foaming reaction conditions to final properties. Each studied CBA is discussed with clear advantages and drawbacks and presented in order to give insights for both scientific and industrial communities. This document has also the ambition to give perspectives concerning development of several CBAs.

Firstly, inorganic chemical blowing agents will be presented and discussed. Secondly presentation and discussion of the commercial organic blowing agent will be given. The last part will present some new CBAs, either inorganic or organic. This last part will present not only new efficient CBAs but also perspective and promising substance that could help to draw the future of the CBA chemistry. 


\section{Inorganic Chemical Blowing Agents}

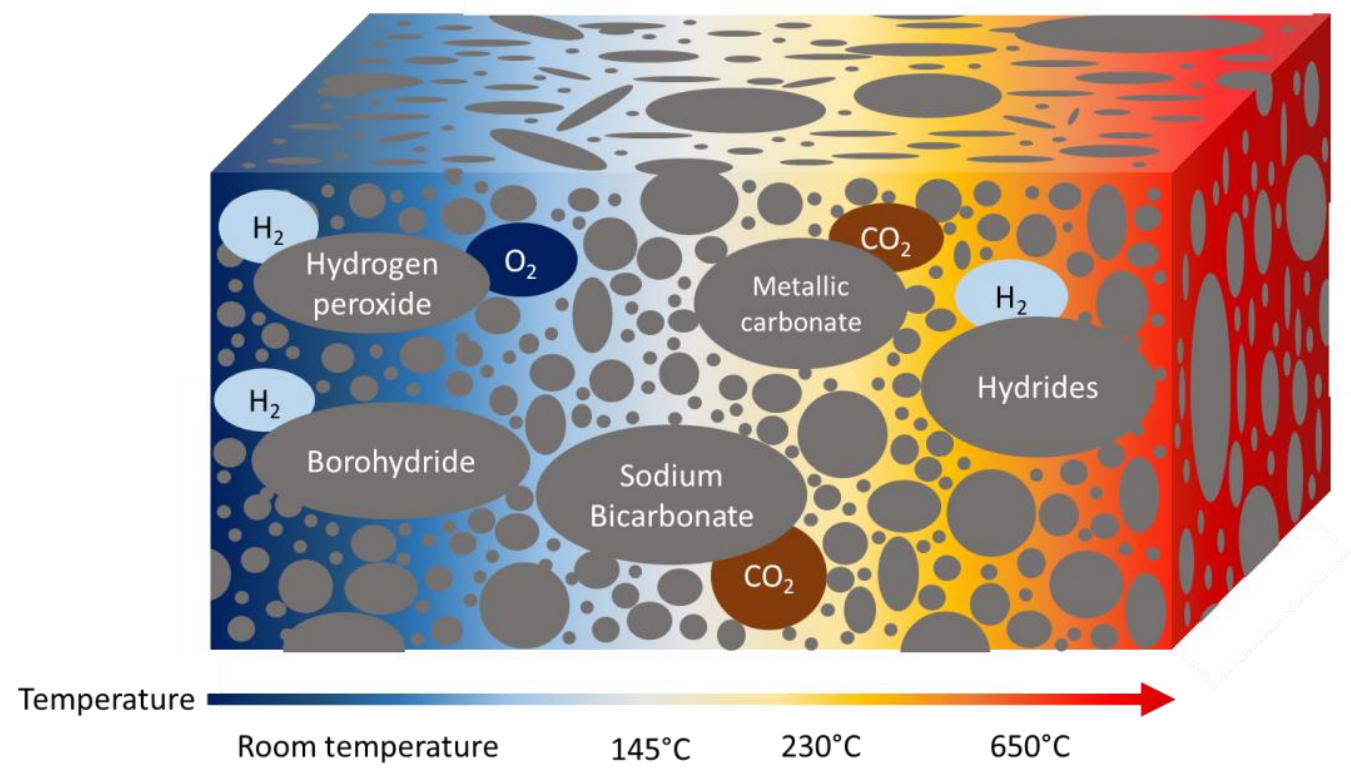

Figure 1: Different ICBAs and the gases produced depending on the temperature

As mentioned previously, CBAs are organic or inorganic compounds with the ability to release gas under specific conditions. Inorganic CBAs (ICBAs) represent a minor part of CBAs and are often referred to as endothermic CBAs. Nevertheless, ICBAs allow the synthesis of foams under different conditions, leading to materials with diverse properties.

\section{1) Carbonates}

The carbonates are usually referenced as the most used ICBAs due to the use of sodium carbonate/ citric acid. Additionally they are also appreciated for the production of carbon dioxide.

a. Sodium Bicarbonate

Sodium bicarbonate, $\mathrm{NaHCO}_{3}$ or sodium hydrogen carbonate, is the most well-known endothermic blowing agent. It is widely used in both industry and academic communities, due to its low cost, mild temperature of reaction and the release of carbon dioxide $\left(\mathrm{CO}_{2}\right)$, a non-toxic and highly stable gas (scheme 1). Indeed, the sodium carbonate is generally used with citric acid and both components are recognized safe for food contact usage. ${ }^{20}$ Sodium bicarbonate can also be used with formic acid. ${ }^{21}$ The thermal decomposition of the sodium bicarbonate yields carbon dioxide, water and sodium carbonate. The decomposition takes place under relatively mild temperatures between $145^{\circ} \mathrm{C}$ and $150^{\circ} \mathrm{C}$ (Figure 1). 


$$
\begin{gathered}
2 \mathrm{NaHCO}_{3} \stackrel{\Delta}{\longrightarrow} \mathrm{Na}_{2} \mathrm{CO}_{3}+\mathrm{CO}_{2} \uparrow_{(\mathrm{g})}+\mathrm{H}_{2} \mathrm{O} \\
\mathrm{NaHCO}_{3}+\mathrm{NH}_{4} \mathrm{Cl} \stackrel{\mathrm{rt}}{\longrightarrow} \mathrm{NaCl}+\mathrm{NH}_{3} \uparrow_{(\mathrm{g})}+\mathrm{CO}_{2} \uparrow_{(\mathrm{g})}+\mathrm{H}_{2} \mathrm{O}
\end{gathered}
$$

Scheme 1: Thermal decomposition of sodium bicarbonate (a); reaction between sodium bicarbonate and ammonium chlorine (b)

Because of the high diffusion rate of $\mathrm{CO}_{2}$, foams with open-cell structure are generally obtained. Open-cell structure is usually suitable for epoxy polymer ${ }^{22}, \mathrm{PVC}^{23}$ or rubber foam. ${ }^{24}$ Theoretically, sodium bicarbonate yields $267 \mathrm{~cm}^{3} / \mathrm{g}$. However, Heck et al. presented a general yield around 135 $\mathrm{cm}^{3} / \mathrm{g}$, the authors did not give any relevant explanations of this difference. This lower yield could be explained by a non-total decomposition. Thus if the conversion is not total, we could consider that a "gas tank" remains available in the material with the presence of residual ICBA, which can be a problem if extra gas is released during working conditions. ${ }^{25}$ Usually sodium bicarbonate is used under mild temperature. However, some studies showed the use of this BA at room temperature. Hence, Uy Lan et al. ${ }^{26}$ reported the synthesis of epoxy foams where the foaming step was carried out at room temperature with sodium bicarbonate (Figure 2). The obtained foams had densities between $0.340 \mathrm{~g} / \mathrm{cm}^{3}$ and $0.640 \mathrm{~g} / \mathrm{cm}^{3}$ depending on the formulation. The sodium bicarbonate reacted with ammonium chloride in order to produce carbon dioxide and ammonia $\left(\mathrm{NH}_{3}\right)$, (Figure 1, equation $b$ ). This gas releasing reaction is interesting but $\mathrm{NH}_{4} \mathrm{Cl}$ could also yield hydrogen chloride $(\mathrm{HCl})$ and $\mathrm{NH}_{3}$ when heated at high temperature. Moreover, the release of ammonia is a question due to its toxicity. Furthermore, two concomitant by-products are formed, water and sodium chloride salt. The resulting foam was washed with water in order to remove the formed salt, which added a purification step. This process showed serious drawbacks such as the toxicity of the released gas or the presence of residues in the foam and should be limited to non-water sensitive compounds.

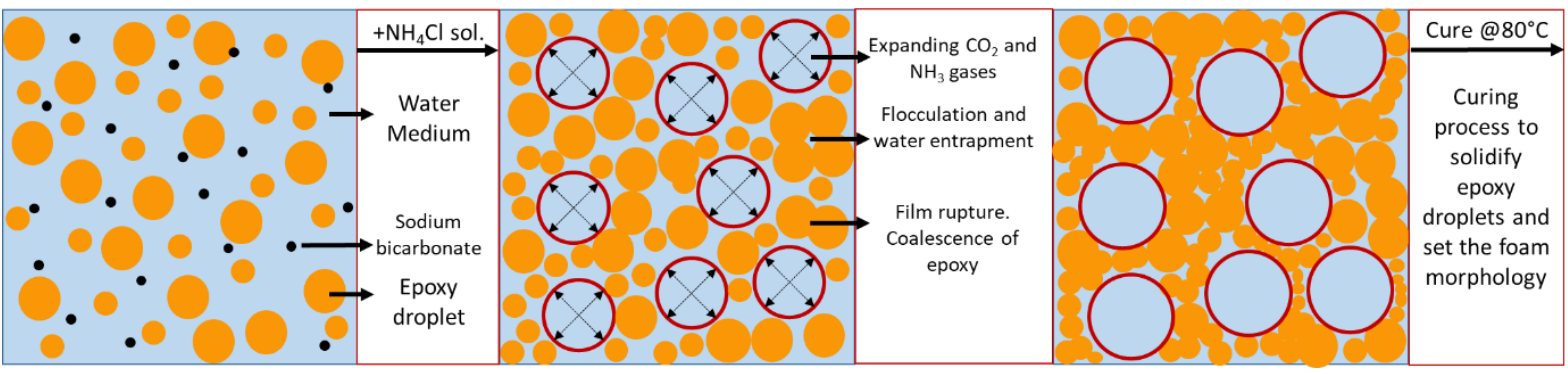

Figure 2: Aqueous emulsion foaming mechanism ${ }^{26}$

Other studies showed the use of sodium bicarbonate/acid mixture as CBA. Hence, Karlsson et al. ${ }^{27}$ presented an extrusion process in order to blow $\beta$-glucan foams. The obtained foams were processed between $110^{\circ} \mathrm{C}$ and $150^{\circ} \mathrm{C}$ and the densities of the foams were comprised between $0.55 \mathrm{~g} / \mathrm{cm}^{3}$ and $1.2 \mathrm{~g} / \mathrm{cm}^{3}$. The foam structure was mainly composed of open cells, which could result from lack of nucleating agent additives. Altuna et al. presented the synthesis of bio-based epoxy foams using sodium bicarbonate at $140{ }^{\circ} \mathrm{C}$. The obtained foams had a wide range of densities from $0.160 \mathrm{~g} / \mathrm{cm}^{3}$ to $0.550 \mathrm{~g} / \mathrm{cm}^{3} .^{28}$ Using a commercial CBA containing sodium carbonate as blowing molecule, called Hydrocerol ${ }^{\otimes}$ CT3108, Julien et al. ${ }^{29}$ blew poly(lactic acid) foam. The foaming process occurred at 170 ${ }^{\circ} \mathrm{C}$ and the final materials contained from $3 \%$ to $20 \%$ of open cells. The obtained foams had a density between 3 and 26 cells $/ \mathrm{cm}^{3}$. The structure of the foams seemed more homogeneous than the foams 
obtained by Karlsson et al. due to the presence of nucleating agent additives, which improved the structure of the material. The advantage of both research studies lies in the use of a CBA in biopolymers to release carbon dioxide. The use of renewable resources in green chemistry is highly studied at the moment, for example Xi et al. presented a glucose-based non-isocyanate polyurethane foam using sodium bicarbonate and managed to decrease the density of the foam. ${ }^{30}$ Nevertheless high temperatures are required to blow the foams. Sodium bicarbonate has also been used in order to blow metallic foams. Hence, Alioux et al. ${ }^{31}$ presented a process where sodium bicarbonate has been dispersed in a mixture of metallic nanoparticles and glycerol. The mixture was immersed in a hydrogen chlorine bath where the sodium hydrogen carbonate reacted with $\mathrm{HCl}$ in order to yield carbon dioxide, water and sodium chloride. The study showed the influence of the $\mathrm{HCl}$ concentration on the expansion volume. Indeed $0.1 \mathrm{M}$ of $\mathrm{HCl}$ allowed a volume expansion of 1.7 times whereas $10 \mathrm{M}$ led to 23 times. This work is particularly interesting because it was applied to metallic foams. However, the use of $\mathrm{HCl}$ implied the use of hazardous chemical. The interest of the industry toward sodium carbonate as CBA is also demonstrated with patents filled by several companies with various polymers such as polycarbonate ${ }^{32}$, PVC plastisol ${ }^{33}$ and low density polyethylene ${ }^{34}$. Thus sodium carbonate is widely used as CBA despite the formation of residues and the open-cell structure due to the carbon dioxide formation. ${ }^{25}$

\section{b. Zinc Carbonate and other metal carbonates}

As mentioned previously, carbonate salts release carbon dioxide. The interest of zinc carbonate is the thermal decomposition which releases carbon dioxide and zinc oxide (scheme 2). Therefore, these ICBAs are used to blow moisture sensitive polymers such as polycarbonates. However, the chemical decomposition takes place under high temperatures from $225^{\circ} \mathrm{C}$ to $245^{\circ} \mathrm{C}$.

$$
\mathrm{ZnCO}_{3} \stackrel{\Delta}{\longrightarrow} \mathrm{ZnO}+\mathrm{CO}_{2} \uparrow(\mathrm{g})
$$

Scheme 2: Zinc Carbonate thermal decomposition

Zinc carbonate is generally used in order to blow cross-linked PVC foams. ${ }^{35}$ Recently a patent claimed the use of zinc carbonate in order to blow epoxy foams. ${ }^{36}$ However, this ICBA is industrially used in blends formed with common CBAs such as azodicarbonamide. Both blowing and nucleating agent roles can interestingly be related to the zinc carbonate. ${ }^{37}$ The nucleating agent is used in order to improve the cell structure within the foam. ${ }^{38}$ However, zinc oxide is an eco-toxic substance which may limit the use of zinc carbonate in industrial applications. ${ }^{39}$ Many carbonate salts can be produced using various alkaline earth metals. Additionally, Oveisi et $a l .^{40}$ presented the calcium carbonate as an efficient BA for aluminum materials where the foam process took place at $1,000^{\circ} \mathrm{C}$. Barium carbonate can be used as blowing agent too. Hence, Paswan et al..$^{41}$ showed the barium carbonate efficiency for iron foam. The foaming process occurred at $1,350^{\circ} \mathrm{C}$ and was compared to some carbonates as strontium carbonate and magnesium carbonate. However, their use is limited due to their decomposition temperature, $630^{\circ} \mathrm{C}$ for $\mathrm{CaCO}_{3}, 945^{\circ} \mathrm{C}$ for the $\mathrm{SrCO}_{3}$ and $1,045^{\circ} \mathrm{C}$ for the $\mathrm{BaCO}_{3}$. Therefore, $\mathrm{ZnCO}_{3}$ is the most used metal carbonate as blowing agent. These blowing agents are always processed at high temperature, but the range of metal available could be a possibility to found another useful salt. Despite this possibility, such metal carbonate BAs are expensive. Hence their price is directly linked to the metal price. There is not a lot of other BAs able to reach this 
decomposition temperature, thus even if the price is higher than usual CBAs, for some foam their use is essential.

2) Borohydride compounds

Borohydrides have historically proven to be efficient blowing agents for polymer foams. ${ }^{42}$ Indeed sodium or potassium borohydrides, well known compounds, release hydrogen under aqueous, acid conditions, and high temperatures $\left(600^{\circ} \mathrm{C}\right)$, or in presence of metallic ions (scheme 3$)^{43}$

$$
\mathrm{NaBH}_{4}+\mathrm{H}_{2} \mathrm{O} \underset{\mathrm{rt}}{\stackrel{\text { cat. }}{\longrightarrow}} \mathrm{NaBO}_{2}+2 \mathrm{H}_{2} \uparrow_{(\mathrm{g})}
$$

\section{Scheme 3: Sodium Borohydride reaction with water}

The large amount of gas released compare to regular nitrogen-releasing CBAs makes them highly efficient and very attractive. Indeed, reaction of sodium borohydride with water produces more than $2,000 \mathrm{~cm}^{3} / \mathrm{g}$ of hydrogen when citric acid/sodium bicarbonate mixture produces only $\approx 130 \mathrm{~cm}^{3} / \mathrm{g}$ of $\mathrm{CO}_{2} \cdot{ }^{44,25}$ The reaction produces hydrogen and a colorless solid named sodium metaborate. In the late 50 's a process using acidic aqueous conditions with sodium borohydride was commercialized by Goodrich in order to blow vinyl polymers. ${ }^{42}$ Sodium borohydride has also been described by Wade et $a .^{44}$ as efficient blowing agent for epoxy foams (density from $0.04 \mathrm{~g} / \mathrm{cm}^{3}$ to $0.22 \mathrm{~g} / \mathrm{cm}^{3}$ ) and PVC plastisol (density $0.3 \mathrm{~g} / \mathrm{cm}^{3}$ ). Sodium borohydride was also described in a US patent ${ }^{45}$ as an efficient BA for PU foams. The PU foam exhibited a density of $0.05 \mathrm{~g} / \mathrm{cm}^{3}$. Unsaturated polyesters were blown using sodium borohydride owing to another US patent. ${ }^{46}$ However, despite their high gas release yields, these ICBAs release hydrogen, a highly flammable gas which limits their usage. Moreover, in the same period, the price of borohydrides increased significantly compare to other carbonates previously mentioned, which also drastically limited their usage in industry. Thus, nowadays these CBA are hardly used in industry and are mainly used in academic studies.

3) Hydrogen peroxide

Hydrogen peroxide or $\mathrm{H}_{2} \mathrm{O}_{2}$ is a low cost, thermodynamically unstable CBA. Hydrogen peroxide releases oxygen gas and water in alkaline conditions. Even if hydrogen peroxide is a cheap, low energy CBA, its instability and the production of highly flammable gas are important drawbacks for both storage, transportation and use in industry. Besides its hazardous aspect, hydrogen peroxide is generally used in inorganic foams. Indeed, Feng et al. presented a study using hydrogen peroxide in order to create porosity in geopolymers (figure 3$).{ }^{47}$ 


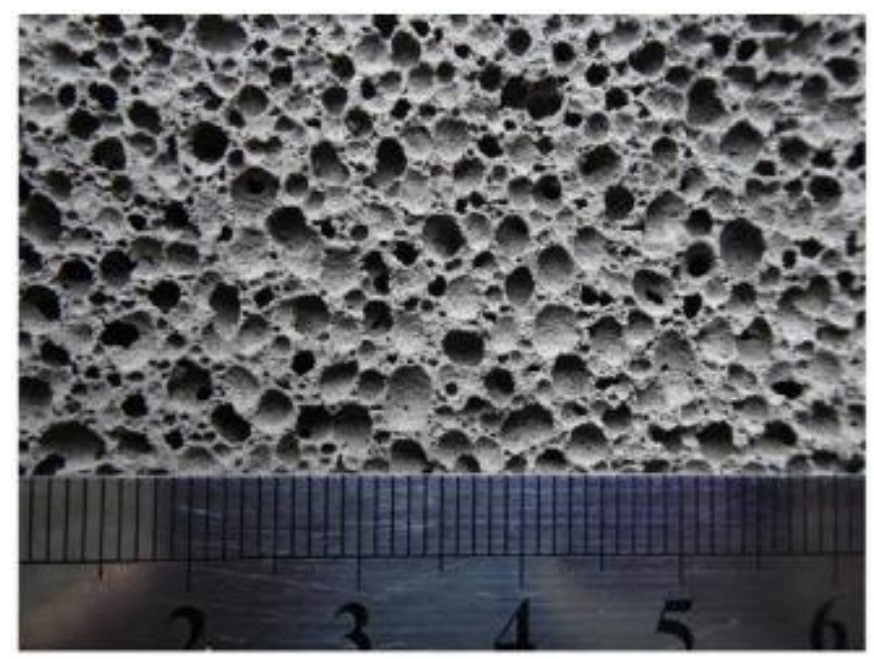

Figure 3: Geopolymer foam obtained by Feng et al. ${ }^{47}$ (conditions: $80 \mathrm{~g}$ of water, $55^{\circ} \mathrm{C}, 6 \mathrm{~g}$ of $\mathrm{H}_{2} \mathrm{O}_{2}$ )

Moreover, other teams showed interest in geopolymers blown with $\mathrm{H}_{2} \mathrm{O}_{2}$ as Petlichkaia et al. ${ }^{48}$ Recently Rao et al. $^{49}$ presented a silica-alumina foam blown using hydrogen peroxide. Thus, gas production requires harsh conditions such as oxidizing agent and alkaline system that are not suitable for polymers and this blowing agent is limited to inorganic foams.

4) Hydrides

Some hydrides are described as blowing agents, e.g. magnesium hydride for aluminum foams. ${ }^{50}$ The usual thermal decomposition of metal hydride is used to produce hydrogen. However, this decomposition takes place under high temperature e.g. $650^{\circ} \mathrm{C}$ for titanium hydride or $\mathrm{TiH}_{2} .{ }^{51}$ The thermal decomposition of hydrides is the most common process. It allows the foaming process of metallic foams (figure 4). ${ }^{52}$ Nevertheless, few studies presented a different pathway to obtain hydrogen from hydrides. As example, Chao et al. reported the reaction of magnesium hydride with water (scheme 4$).^{53}$ However, the concept of reacting hydride with water in order to produce hydrogen is not new, since in 1996 Leckey et al. studied the reaction of lithium hydride with water. ${ }^{54}$

$$
\mathrm{MgH}_{2(\mathrm{~s})}+2 \mathrm{H}_{2} \mathrm{O}_{(\mathrm{l})} \longrightarrow \mathrm{Mg}(\mathrm{OH})_{2(\mathrm{~s})}+\mathrm{H}_{2} \uparrow_{(\mathrm{g})}
$$

\section{Scheme 4: Reaction between magnesium hydride and water}

Nevertheless, the interest of the research scientists toward hydride reaction with water has recently found a second breath. Indeed, the use of hydrides as hydrogen storages in order to power fuel cells has recently increased attention..$^{55}$ Thus, these researches could be applied to foam industry using nanoparticles of chemical hydrides reacting with moisture in order to obtain a foam.

Hydrides are all the more interesting since they could react with ambient moisture in order to produce gas. This reaction could be applied to blow foams based on reaction such as isocyanate and water reaction. The reaction between hydrides and water is still in development in academic and industrial research teams but the focus is not necessary on foaming process. 


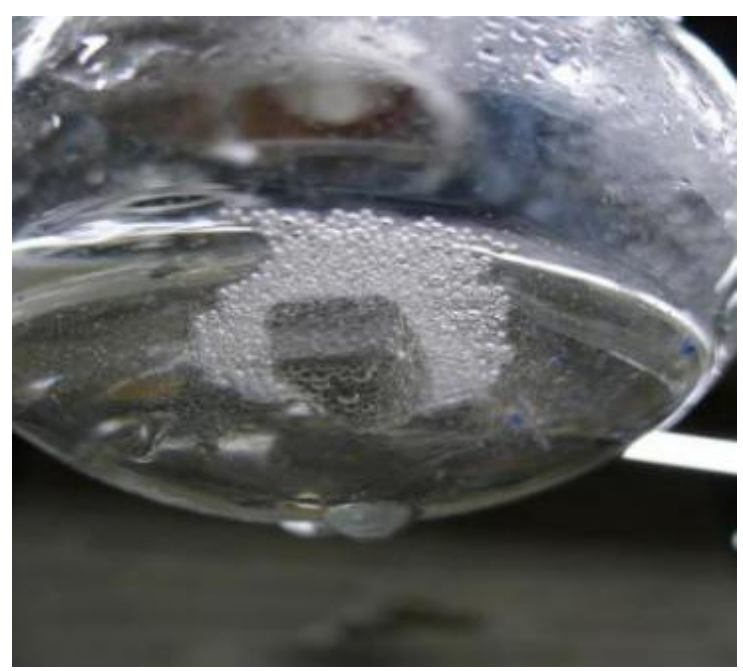

Figure 4: Bubbles from the chemical reaction of Magnesium Hydride and Water in acid conditions ${ }^{52}$

5) Conclusion

Table 1: Properties of ICBA

\begin{tabular}{|c|c|c|c|c|}
\hline ICBA & $\begin{array}{c}\text { Temperature } \\
\left({ }^{\circ} \mathrm{C}\right)\end{array}$ & $\begin{array}{c}\text { Gas } \\
\text { produced }\end{array}$ & $\begin{array}{l}\text { Gas Yield } \\
\left(\mathrm{cm}^{3} / \mathrm{g}\right)\end{array}$ & Foams \\
\hline $\begin{array}{l}\text { Sodium } \\
\text { Bicarbonate }\end{array}$ & 145 & $\mathrm{CO}_{2}, \mathrm{H}_{2} \mathrm{O}$ & $135-260$ & $\begin{array}{c}\text { PVC foams }{ }^{22} \text {, epoxy } \\
\text { foams }{ }^{23} \text {, rubber foams s" } \\
\text { PE low density }{ }^{56}\end{array}$ \\
\hline Metallic Carbonate & $<600$ & $\mathrm{CO}_{2}$ & - & $\begin{array}{c}\text { PVC foams }{ }^{35} \text {, epoxy } \\
\text { foams }^{36}\end{array}$ \\
\hline Borohydride & 600 & $\mathrm{H}_{2}$ & 2000 & $\begin{array}{c}\text { PVC foams }{ }^{44}, \text { epoxy } \\
\text { foams }^{44}, \mathrm{PU} \text { foams } \\
\text { polyester foams }^{46}\end{array}$ \\
\hline Hydrogen peroxide & 50 & $\mathrm{O}_{2}$ & - & Geopolymer foam $^{47-49}$ \\
\hline Hydrides & 650 & $\mathrm{H}_{2}$ & - & $\begin{array}{c}\text { Metallic foams }{ }^{50-52} \text { (Al, } \\
\mathrm{Zn} \text {, Tin, etc.) }\end{array}$ \\
\hline
\end{tabular}

Many inorganic pathways have emerged to provide a wide choice of suitable ICBAs. The main advantage of using ICBAs, is their high gas yield. The several ICBAs presented allowed a wide range of uses in various polymers but also in inorganic foams. 


\section{Organic Chemical Blowing Agents}

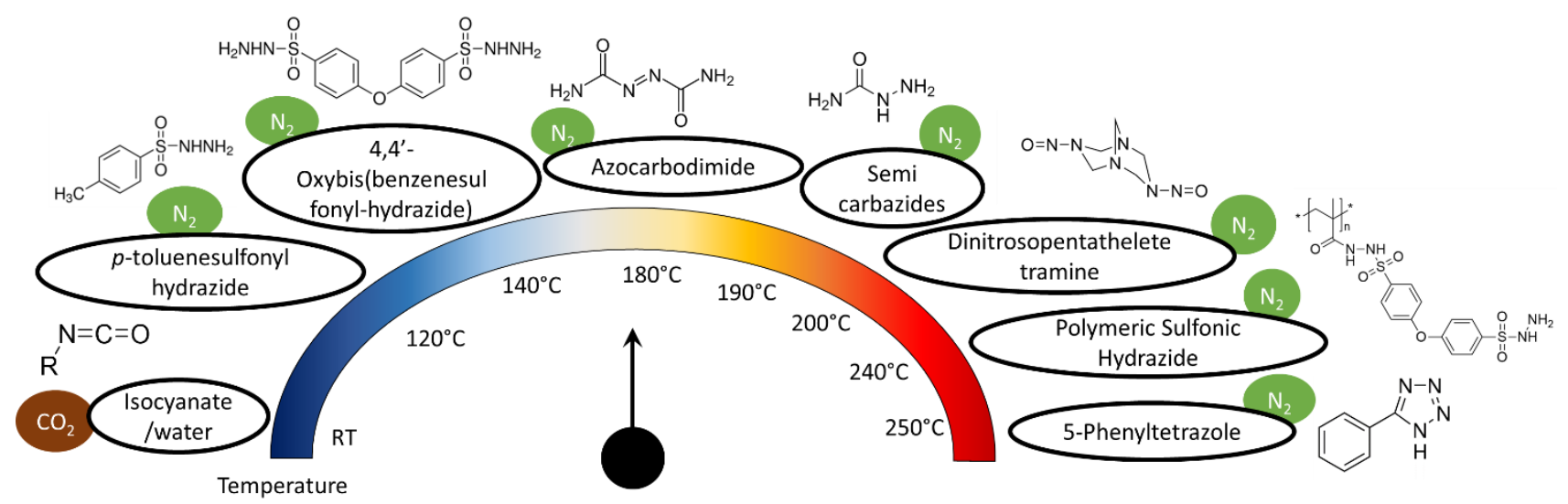

Figure 5: Main OCBA and their produced gas depending on the temperature

The previous part reported most used ICBAs, which yet represent a minor part of the general use of CBAs. The following part will present Organic Chemical Blowing Agent (OCBA), the most interesting part of the CBA research and use nowadays.

1) Isocyanate and Water

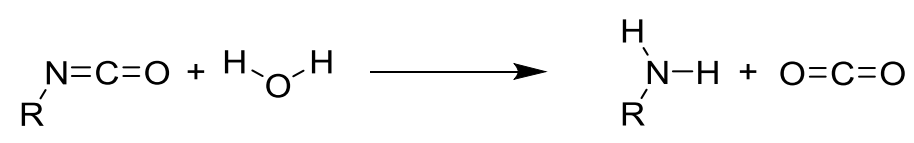

Scheme 5: Reaction between isocyanate and water

Among all the CBA systems, the reaction between isocyanate and water is one of the most widely reported and used (scheme 5). This reaction is particularly attractive because it produces carbon dioxide, an inert, non-flammable and non-toxic gas. The reaction with water produces $\mathrm{CO}_{2}$ and the amine corresponding to the reactant isocyanate, which could react with another isocyanate to yield urea moiety. The presence of the urea is the main drawback of the isocyanate/water reaction because the urea could have strong influence on the polymer properties. This reaction occurs easily at room temperature allowing the self-blowing of PU foams. The high reactivity of isocyanate allows the reaction even with moisture, hence liquid water is not necessary to obtain a foam. Nevertheless, in order to obtain a PU structure, polyols are needed to react also with isocyanates and yield a thermoset. Thus, the kinetics of both reactions has to be optimized in order to obtain a correct foam structure. However, a competition between the curing reaction and the blowing reaction generally occurs. In order to avoid this competition, catalysts were developed to improve the selectivity of the reaction toward the curing reaction. Organotin catalysts are preferred for PU synthesis in water for example. ${ }^{57}$ The numerous patents filled show the high interest of industry for this CBA couple. ${ }^{58-61}$ However, toxicity of isocyanates is nowadays a limitation to their use $\mathrm{e}^{62-65}$ and the industry is paying increasing attention to alternatives. For the moment, the main alternatives are the use of biobased polyols and isocyanates to blow PU foams. The different reviews from Furtwengler et al. gave a good overview of the different works carried out on this topic. ${ }^{66,67}$ Gwon et al. ${ }^{68}$ developed PU foams blown using isocyanate and water as blowing agent and used several catalysts as gelling agents in order to obtain the best structure. Their aim was to obtain a foam for acoustic insulation, hence they 
focused on closed-cell structures. The foams density ranged from 50 to $70 \mathrm{~g} / \mathrm{cm}^{3}$. The use of isocyanate and water reaction is not restricted to PU material, it can be used in order to blow other foams. Chruściel et al. ${ }^{61}$ showed silicone foams blown using reaction between isocyanate and water. The obtained foams had densities from 0.25 to $0.66 \mathrm{~g} / \mathrm{cm}^{3}$. Sun et al. presented a study using isocyanate as CBA among polyimide foam, the obtained foam had densities around $0.048 \mathrm{~g} / \mathrm{cm}^{3}$.

2) Azo-compounds

Azodicarbonamide (ADC) and its few blends (mixtures with inorganic CBAs for example) is the most widely used CBA in the world. In the 2000s it accounted for almost $90 \%$ of the CBAs used in Western Europe. ${ }^{8}$<smiles>NC(=O)N=NC(N)=O</smiles>

Scheme 6: Decomposition of azocarbonamide under thermal conditions

Most of the applications of this CBA are found in thermoplastic and rubber industry. The popularity of this CBA comes from its ability to adapt to a wide range of processes. Additionally, it is commercially available in three forms: powder, formulated powder with additives and pre-dispersed powder in a material. The most basic form of $A D C$ is a fine yellow powder. This yellow powder basically yields around $230 \mathrm{~cm}^{3} / \mathrm{g}$ of gas. The ADC powder is classified by grade, the powder grade corresponds to the particles size, from 3 to $30 \mu \mathrm{m}$. Thus, it leads to an apparent density from 0.3 to $0.70 \mathrm{~g} / \mathrm{cm}^{3}$, which corresponds from high to medium foam density. The main interest of the particles size range is the effect on the surface area. As the particles size decreases, the surface area improves and thus the interactions with additives are enhanced. ${ }^{19}$ The interactions with additives could lead to a reduction of the blowing temperature or an improved texture. ADC usually produces gas under thermal decomposition (scheme 6). The compounds generally decompose at $230{ }^{\circ} \mathrm{C}$ to produce nitrogen, carbon monoxide, carbon dioxide and ammonia in various ratios. ${ }^{25} \mathrm{It}$ has been proved that the addition of $4,4^{\prime}$-oxybis(benzenesulfonylhydrazide) reduces the ADC decomposition temperature to $205{ }^{\circ} \mathrm{C}$. Nevertheless, $205^{\circ} \mathrm{C}$ is a temperature much higher than the usual temperature for processing plastics (PVC is typically processed around $180^{\circ} \mathrm{C}$ ). Thus activators such as zinc oxide, zinc stearate, urea or benzoate, are used in order to lower the decomposition temperature by $40{ }^{\circ} \mathrm{C} .{ }^{70}$ Due to the use of additives and the several grades of powder, it is possible to tune the decomposition temperature which explains the wide use of this compound. For example, Michałowski et al. presented a foaming process of PVC using ADC as CBA under microwave irradiation. ${ }^{71}$ The obtained foams had densities from $0.815 \mathrm{~g} / \mathrm{cm}^{3}$ to $0.915 \mathrm{~g} / \mathrm{cm}^{3}$. A lot of patents and publications were published using this $\mathrm{CBA}$, demonstrating the interest of both academic and industrial scientists. ${ }^{72-76}$ Furthermore, $A D C$ is not the only azo-compound used, for example, azobisisobutyronitrile (scheme 7) ${ }^{61,77}$, diisopropyl azodicarboxylate (scheme 7$)^{78}$ are also azo CBAs used for diverse applications.<smiles>CC(C)(C#N)N=NC(C)(C)C#N</smiles><smiles></smiles> 
Azobisisobutyronitrile could also be an interesting alternative to the ADC but it has to be stored under low temperature and away from light to avoid radical decomposition, which can be a serious drawback. Moreover, diisopropyl azodicarboxylate is classified as toxic. Thus it could explain the low use of this molecule as CBA. Hence, despite the production of harmful gas during the decomposition reaction, azodicarbonamide is widely used in industry due to its high adaptability to diverse processes. Nevertheless, even if few CBAs from this azo family were developed, they remain less attractive than the ADC.

3) Hydrazine Derivatives

Hydrazine derivatives decomposition generally leads to water and nitrogen at relatively low temperature. The decomposition range is comprised between $110{ }^{\circ} \mathrm{C}$ and $160^{\circ} \mathrm{C}$. This relatively low decomposition temperature makes hydrazine derivatives popular CBAs. Hydrazine derivatives are used to blow polymers requiring low temperature process. Among hydrazine derivatives, 4,4'oxybis(benzenesulfonyl-hydrazide) (OBSH) and $p$-toluenesulfonyl hydrazide (TSH) are the most used blowing agents ${ }^{61,79-85}$. The thermal decomposition of OBSH takes place around $140{ }^{\circ} \mathrm{C}$ when the TSH decomposes at $120^{\circ} \mathrm{C}$. OBSH generally yields from to 120 to $150 \mathrm{~cm}^{3} / \mathrm{g}$ of gas when TSH leads to 115 $\mathrm{cm}^{3} / \mathrm{g}$. OBSH, has been widely used, despite its high toxicity, due to the formation of non-volatile and non-toxic oligomeric residues during the decomposition. ${ }^{8}$ These two CBAs were widely used among rubbers since they induce a mercaptan-like odor which is detrimental in many other materials, e.g. PVC foams. TSH has been described as flammable, but despite this concern, it has been widely used, mainly for rubber materials. ${ }^{19} \mathrm{OBSH}$ and TSH have some drawbacks such as the lack of compatibility with polymers and the difficulty to control the cell size. Thus, in order to improve the compatibility of low molar mass BA with polymers, these BA have been encapsulated in what is called masterbatch. The masterbatch is then dispersed in the raw material, then, during the process the encapsulated molecules are released, and produce gas. Nevertheless, it results in a higher price and it is not efficient for all polymers. Thus polymeric blowing agents have been developed as an alternative to improve the compatibility with polymers. Some studies presented the CBA grafted on silane coupling agent via aqueous radical polymerization in order to promote the dispersion in polypropylene. ${ }^{82}$ 


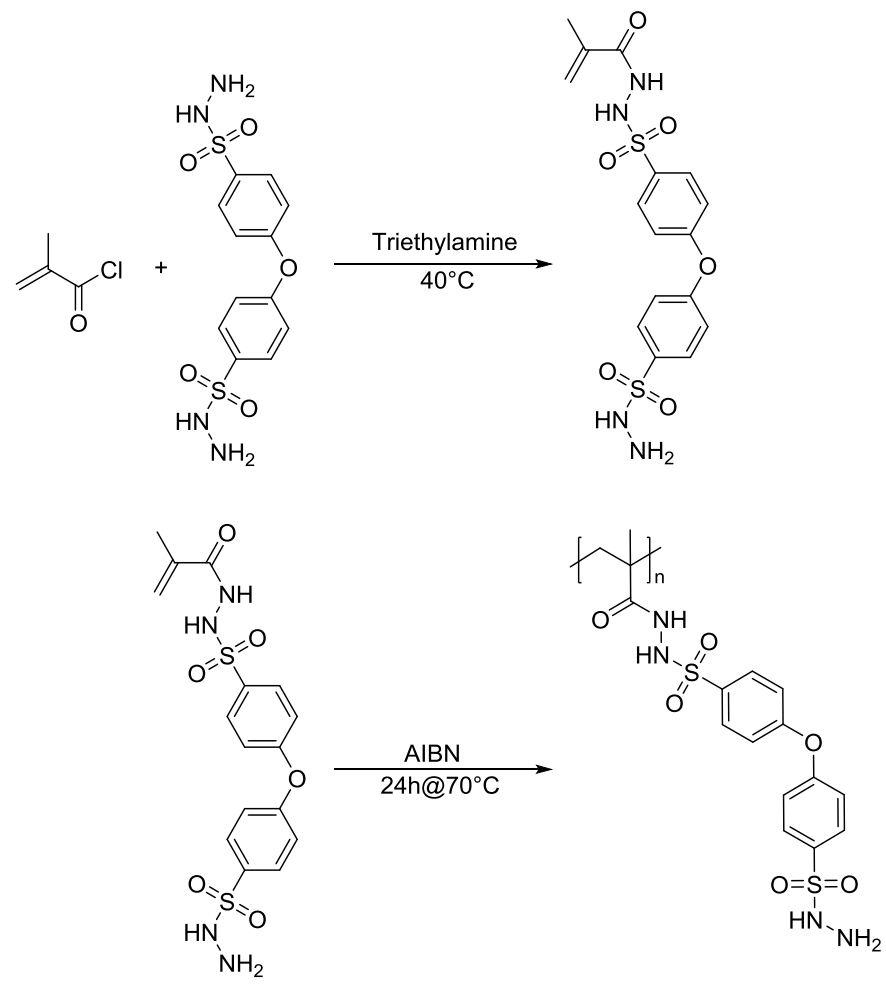

Scheme 8: Synthesis of the polymeric CBA 85

Jeong et $a .^{86}$ presented the synthesis of a new polymeric foaming agent based on sulfonyl hydrazide moiety (scheme 8). This BA was interesting since its decomposition led to polymer residues with nitrogen and water. The decomposition took place at higher temperature than usual OBSH or TSH, e.g. $240^{\circ} \mathrm{C}$. The increase in decomposition temperature was attributed to the release of sulfonic acid from the polymer backbone at high temperature (scheme 9). Nevertheless, this temperature can be lowered using activators. The amount of gas released was $74 \mathrm{~cm}^{3} / g$. The yield was logically lower than the usual hydrazine CBA due to the higher molar mass of the polymeric CBA and the incorporation of the methacrylic unit in the monomer unit. 


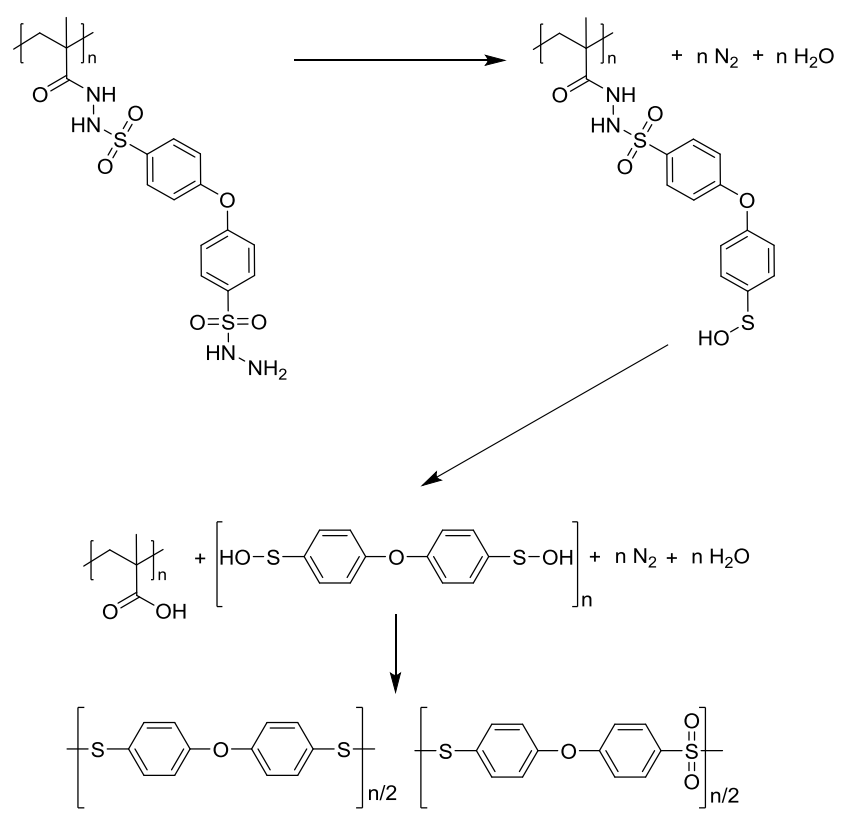

Scheme 9: Thermal decomposition of the polymeric foaming agent ${ }^{85}$

Several problems of compatibility between CBA and polymer have been reported. ${ }^{87}$ Hence, the use of a polymeric form led to a better compatibility between the plastic matrix and the polymeric BA. However, a lower amount of gas is released by a polymeric BA. Nevertheless, the obtained ethylenevinyl acetate (EVA) foams showed morphological aspects as good as $\mathrm{OBH}$ (figure 6).

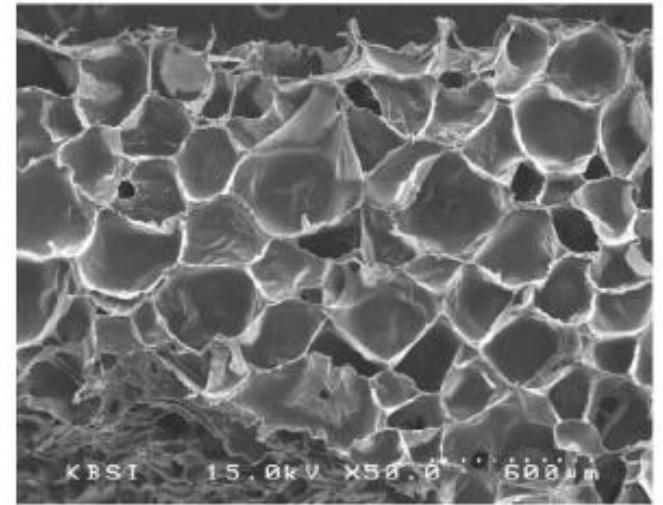

(a)

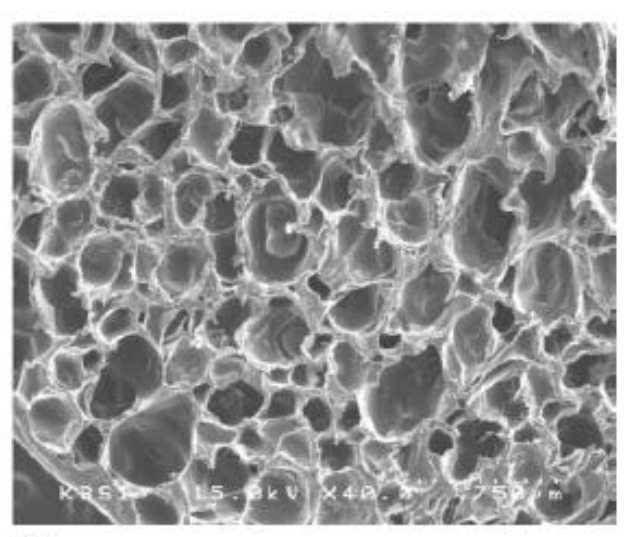

(b)

Figure 6: SEM images after foaming of the cross-linking area of EVA sponges incorporating (a) OBSH and (b) Polymeric Blowing Agent ${ }^{86}$

The same team reported the synthesis of particles of poly(methacryloyl toluenesulfonylhydrazide) as blowing agent. ${ }^{88}$ Hence, for Jeong et al., the interest to use nanoparticles BA was is to improve the specific area of the BA, which led to a faster decomposition, a better dispersion, a reduction of the foaming titration and a more important availability of the CBA. This study showed a thermal decomposition at $240^{\circ} \mathrm{C}$. Thus the decomposition temperature has not been affected by the nanoparticle form of the CBA. However, the precursor of these compounds is hydrazine which is a highly hazardous chemical. ${ }^{89}$ 


\section{4) Azides}

\section{a. Semicarbazides}

Semicarbazides or sulfonyl semicarbazides are exothermic CBAs. Nitrogen and carbon dioxide are the main gases produced by this family of CBAs. The most commercially available semicarbazide is $p$ toluenesulfonyl semicarbazide (scheme 10), which decomposes into $55 \%$ nitrogen, $37 \% \mathrm{CO}_{2}, 3 \% \mathrm{NH}_{3}$ and $2 \% \mathrm{CO}$, with solid residues (3\%) such as ditolyl disulfide and ammonium $p$-toluenesulfonate. ${ }^{90}$ This CBA decomposes generally around $220^{\circ} \mathrm{C}$ but this temperature can be lowered down to $190{ }^{\circ} \mathrm{C}$ using activators such as lead stearate or urea ${ }^{25}$. Another well-known semicarbazide is $4,4^{\prime}$ oxybis(benzenesulfonyl semicarbazide) (scheme 10). These two CBAs were mainly used as high temperature blowing agents (around $220{ }^{\circ} \mathrm{C}$ ). ${ }^{91}$ Both CBAs led usually to $140 \mathrm{~cm}^{3} / \mathrm{g}$ of gas. Semicarbazides were used to blow various polymers such as polyethylene ${ }^{92}$, polyester ${ }^{93}$, polypropylene ${ }^{94}$ or PVC. ${ }^{95}$<smiles>Cc1ccc(S(=O)(=O)NNC(N)=O)cc1</smiles><smiles>NC(=O)NNS(=O)(=O)c1ccc(Oc2ccc(S(=O)(=O)NNC(N)=O)cc2)cc1</smiles>

Scheme 10: p-toluenesulfonyl semicarbazide structure (left) and p-p'-oxybis(benzenesulfonyl semicarbazide) (right)

b. Azides

Azide chemicals are well known compounds in explosive industries. Indeed, due to their high nitrogen content, most of them are unstable. They find usual applications in automotive airbags or rocket propellants. Nevertheless, some industrial patents showed the interest of these chemicals in order to synthesize foams e.g. propylene ${ }^{94}$ or phthalate ${ }^{96}$ foams. Due to the dangerous behavior of these chemicals, very few patents have presented their use as CBA for blowing foams.

\section{5) $N$-nitroso compounds}

$\mathrm{N}$-nitroso compounds have mostly been used in the past decades due to their low cost. The most famous N-nitroso blowing agent is dinitrosopentamethylenetetramine. Such compound leads to ammonia, formaldehyde and nitrogen during thermal decomposition. The decomposition of this kind of CBA occurs around $200{ }^{\circ} \mathrm{C}$ and usually yields to $190 \mathrm{~cm}^{3} / \mathrm{g}$. The use of these CBA was drastically reduced because of the toxicity and the smell of the released gases. ${ }^{8}$ In the past, this compound family was used to blow PVC, PU and rubber foams. ${ }^{91}$ 


\section{6) Tetrazoles}

Tetrazoles are endothermic OCBAs. Hence, they mostly produce nitrogen during their thermal decomposition. The use of tetrazoles as CBAs is particularly interesting in order to blow moisture or ammoniac sensitive foam. The most widely used tetrazole as CBA is 5-phenyltetrazole, a white solid. Its thermal decomposition starts at $250{ }^{\circ} \mathrm{C}$ and can go up to $300{ }^{\circ} \mathrm{C}$. Hence, 5-phenyltetrazole produces $200 \mathrm{~cm}^{3} / \mathrm{g}$ of gas, $98 \%$ of nitrogen and $2 \%$ of ammonia. ${ }^{25}$ The decomposition of this molecule leads to three different co-products: the aminodiphenyltriazole, the 3,5-diphenyl-1,2,4triazole and the triphenyl-5-triazine. Moreover, few analogues of 5-phenyltetrazole decomposes around $370{ }^{\circ} \mathrm{C} .{ }^{97}$ Polycarbonates and polyesters are usually blown using tetrazole CBA. ${ }^{19} \mathrm{~A}$ new tetrazole, 5 -aminotetrazole has been developed by Kiselev et al. This molecule was described as one of the few molecules with highest nitrogen content being thermally stable and non-explosive. ${ }^{98}$ Indeed, 5-aminotetrazole is stable until more than $200^{\circ} \mathrm{C}$, therefore, even if it has not been used in foaming reaction yet, it could be considered as a promising high temperature blowing agent.

7) Conclusion

Table 2: Properties of OCBA

\begin{tabular}{|c|c|c|c|c|}
\hline OCBA & $\begin{array}{l}\text { Temperature } \\
\left({ }^{\circ} \mathrm{C}\right)\end{array}$ & $\begin{array}{c}\text { Gas } \\
\text { produced }\end{array}$ & $\begin{array}{l}\text { Gas yield } \\
\left(\mathrm{cm}^{3} / \mathrm{g}\right)\end{array}$ & Foams \\
\hline Isocyanate/water & RT & $\mathrm{CO}_{2}$ & - & $\begin{array}{l}\mathrm{PU}^{68}, \text { Silicone }^{61} \\
\text { Polyimide }^{69}\end{array}$ \\
\hline Azodicarbonamide & $180-230$ & $\begin{array}{c}\mathrm{N}_{2}, \mathrm{CO}, \\
\mathrm{CO}_{2}, \mathrm{NH}_{3}\end{array}$ & 230 & Rubber, PVC ${ }^{8,71}$ \\
\hline $\begin{array}{c}\text { 4,4'-oxybis } \\
\text { (benzenesulfonyl-hydrazide) }\end{array}$ & 140 & $\mathrm{~N}_{2}$ & 130 & \multirow{2}{*}{$\begin{array}{c}\text { Rubber }^{19}, \\
\text { polypropylene }^{85}\end{array}$} \\
\hline p-toluenesulfonyl hydrazide & 120 & $\mathrm{~N}_{2}$ & 115 & \\
\hline Polymeric Sulfonic Hydrazide & 240 & $\mathrm{~N}_{2}$ & 74 & $\begin{array}{c}\text { Polyethylene } \\
\text { Acetate }^{86}\end{array}$ \\
\hline Semi carbazides & $190-220$ & $\begin{array}{l}\mathrm{N}_{2}, \mathrm{CO}_{2} \\
\mathrm{NH}_{3}, \mathrm{CO}\end{array}$ & 140 & $\begin{array}{c}\text { Polyethylene }^{93}, \\
\text { polypropylene }^{94}, \\
\text { PVC }^{90,95}\end{array}$ \\
\hline Azide & RT & $\mathrm{N}_{2}$ & - & $\begin{array}{l}\text { Propylene }^{84} \\
\text { Phthalate }^{120}\end{array}$ \\
\hline $\begin{array}{c}\mathrm{N}, \mathrm{N}- \\
\text { Dinitrosopentamethylenetetramine }\end{array}$ & 200 & $\mathrm{~N}_{2}$ & 190 & PVC, PU, Rubber ${ }^{91}$ \\
\hline 5-Phenyltetrazole & $250-300$ & $\mathrm{~N}_{2}$ & 200 & $\begin{array}{l}\text { Polycarbonate, } \\
\text { Polyester }^{6}\end{array}$ \\
\hline
\end{tabular}

\section{Original CBA}

The previous parts have presented commercial both organic and mineral CBAs already used for the elaboration of foams in the industry or widely used in academic studies. The following part will 
present recent CBA that were not yet used in industry. The part will also present chemical reactions which could have a promising potential for blowing foams.

\section{1) Metal and strong acid}

Hydrogen production has been described using solid magnesium and aqueous hydrochloric acid. The reaction between the metal and the strong acid (hydrochloric acid, pKa: -6.3) usually occurs in dilute system. Thus the solid by-product magnesium dichloride is then diluted in the aqueous medium. ${ }^{99}$ The low toxicity of the solid magnesium is interesting. However, the use of a strong acid could implies safety drawbacks, e.g. for hydrochloric acid or perchloric acid. However some strong acids are less hazardous such as nitric acid or sulfuric acid. The reaction is interesting since no external energy is needed to obtain the gas. The system could be promising in two-component (2K system) formulations for foams. Polymer containing acetal links shouldn't be use with this CBA system because acidic condition could cleave acetals. ${ }^{100}$. When the acid is mixed in the mold with the solid magnesium it will react in order to blow the foam. Nevertheless, the reaction is usually carried out in solution. Thus the by-produced salt is diluted and easily removed. The main challenge in foams would be to adapt the reaction to bulk materials. The last step would be the washing of the foam like the process presented in the sodium bicarbonate part (part II, 1., A). Additionally, the use of few metals, e.g. zinc, could lead to various CBAs with various properties. ${ }^{101}$

\section{2) Poly(hydrosiloxane)}

Poly(hydrosiloxane) has been recently described as an efficient blowing agent in order to blow both epoxy and poly(hydroxyurethane)s (PHUs) foams. This class of blowing agent is interesting since hydrosiloxane moiety can react with amines to yield silazane group (covalent bond between $\mathrm{Si}$ and $\mathrm{N}$ ) and release hydrogen (scheme 11). Hence, the residue of CBA is covalently bonded to the polymer foam and cannot leach out.

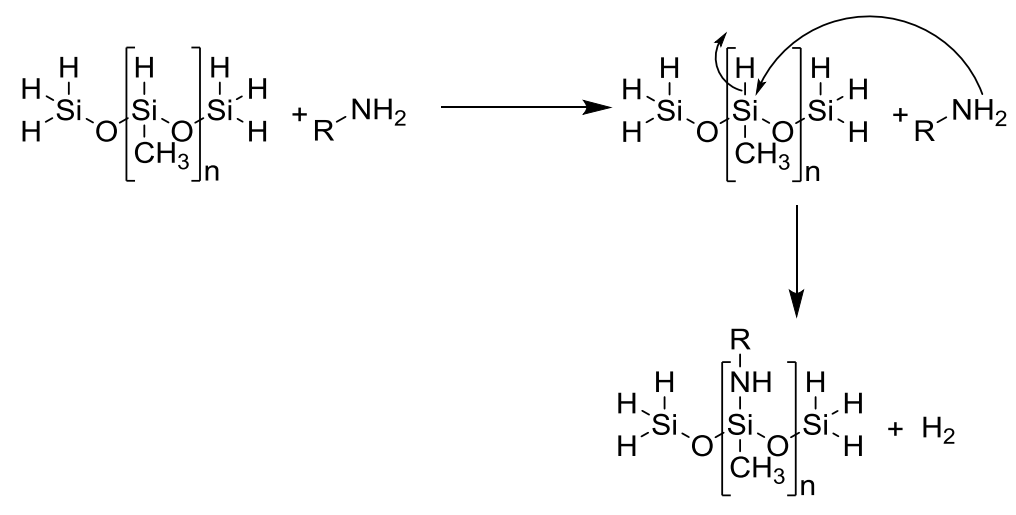

Scheme 11: Reactional scheme of PMHS with a primary amine

Thus, Stefani et al. ${ }^{102}$ reported epoxy foams using siloxane (DY 5054 from Ciba-Geigy) at $50{ }^{\circ} \mathrm{C}$. The CBA reacted with an excess of amine that is also used as epoxy hardener. Several ratios of CBA were tested in order to obtain various foam densities. The study demonstrated that the density decreased when the amount of CBA increased but highlighted that the relation between the CBA and density was not linear (figure 12). The minimum density obtained by the authors was $170 \mathrm{~kg} / \mathrm{m}^{3}$. 


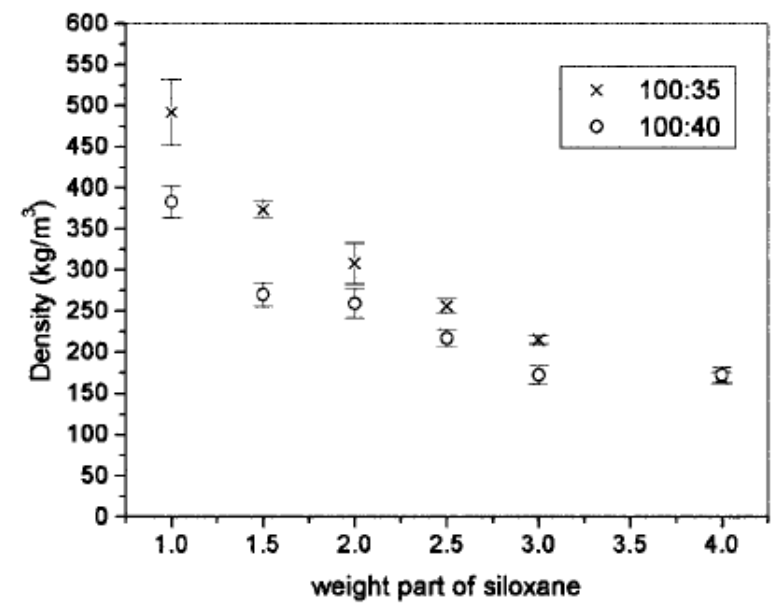

Figure 7: Variation of epoxy foam density in function of the siloxane amount (ratios presented are epoxy:amine)101

More recently, our team ${ }^{103}$ reported the use of poly(methylhydrosiloxane) (PMHS) to blow poly(hydroxyurethane)s at $60^{\circ} \mathrm{C}$. Adding a thiourea catalyst to the PMHS formulation, our team has achieved the synthesis of PHUs foams at room temperature ${ }^{104}$. The curing time was about 3 days which could be a drawback in some industrial applications. However, the main interest of this system is the access to non-isocyanate PU foams in mild conditions and with a non-volatile, non-toxic polymeric residue. Additionally, the use of diamine allowed grafting of PMHS into the polymer network which avoided any specific migration. The amount of available hydrogen atoms along polymer chain is an interesting parameter. The number of hydrogens depends on the molar mass of the polymer. Thus, the amount of gas produced could be chosen using a shorter or longer polymer. Furthermore, the reaction between the amine and siloxane increases the steric hindrance on the available hydrogen environment which could entail in some differences between the theoretical and experimental gas volume released. This CBA has a huge potential in the future despite the production of flammable hydrogen. Some researches need to be carried out in order to determine both the reactivity and the stability of this CBA.

\section{3) Retro Diels Alder}

The Diels-Alder (DA) reaction is not only famous for its possibility to create a carbon-carbon bond but also for its interesting reversibility in mild conditions which found applications in self-healing materials, delivery systems and more recently in dissociative covalent adaptable networks. ${ }^{105}$ This reaction is all the more interesting since depending on the substrates, the retro Diels-Alder (rDA) can yield gases such as nitrogen or carbon dioxide. The following techniques could possibly be used with $\mathrm{PUs}^{106,107}$, polymethacrylates ${ }^{108,109}$ or polyesters ${ }^{110}$ because DA reaction is already used for these types of polymers.

\section{a. Retro Diels-Alder producing nitrogen}

In the late 60's Rieber et al. reported the release of nitrogen as concomitant product of a retro DielsAlder reaction. ${ }^{111}$ Owing to their study the decomposition of diazetine led to nitrogen and 1,3cyclohexadiene. Additionally ,in order to well understand the mechanism, Törk et al. ${ }^{112}$ studied theoretical pathways during the reaction between tetrazine and classical alkene such as ethylene or 
cyclopropene. This work presented the free energies of the several intermediates and explained the release of nitrogen. Nowadays, these reactants are highly interesting notably for their use in click chemistry. A recent study from Pipkorn et al. ${ }^{113}$ showed the use of the retro Diels-Alder reaction in order to form a bio-shuttle. During the formation of the bio-shuttle, nitrogen was co-produced, which implied an irreversible reaction since nitrogen evaporated instantly. The principal interest of the retro Diels-Alder reaction relies on gas release at room temperature. It is an important parameter in order to blow foams under mild conditions. Thus, due to its high reactivity, a two-component system could be envisaged. Moreover, the foaming temperature is not the only advantage. Hence, the reaction produces nitrogen which is a non-flammable, non-toxic and non-odorous gas that presents high interest from a safety point of view (scheme 13). Furthermore, this reaction is the only one producing nitrogen among the original CBAs. Moreover the use of this reaction could imply the incorporation of the CBA in the polymer backbone without any residue formed. Nevertheless, the main drawback is the price since the diene compound is obtained after a multi-step synthesis at high cost. $^{114}$
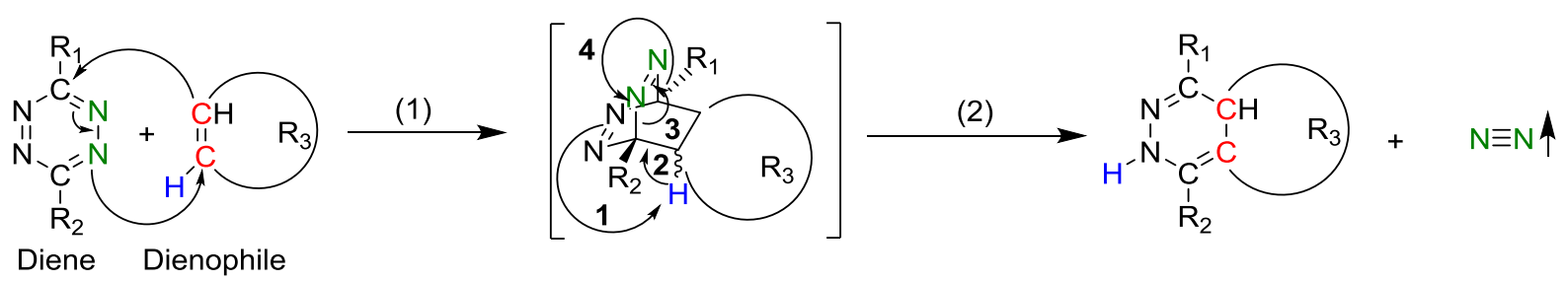

Scheme 13: Simplified mechanism of the Diels-Alder (1) and retro Diels-Alder (2) with nitrogen release.

b. Retro Diels-Alder producing carbon dioxide

In the late 30's Alder et al. described DA reaction of 2-pyrone with a diethyl acetylenedicarboxylate. ${ }^{115}$ Later in the 60's Reed et al. presented a work based on 2-pyrone too. They proved the release of the carbon dioxide during the retro DA. The retro DA took place under high temperature, $\approx 150-250^{\circ} \mathrm{C}$ in dilute system. ${ }^{116}$ More recently, Pfenning et al. focused their work on the study of reactivity and selectivity of rDA on derivatives of 2-pyrone (scheme 14). ${ }^{117}$ During their study they notably showed the use of few catalysts to decarboxylate the derivatives of 2-pyrone, e.g. Lewis acid $\left(\gamma-\mathrm{Al}_{2} \mathrm{O}_{3}\right)$, Brønsted acid (Davisil silica gel) or zeolite. Despite the use of diverse catalysts and conditions (e.g reflux in 1,4-Dioxane), the maximum yield of decarboxylation was around $50 \%$.

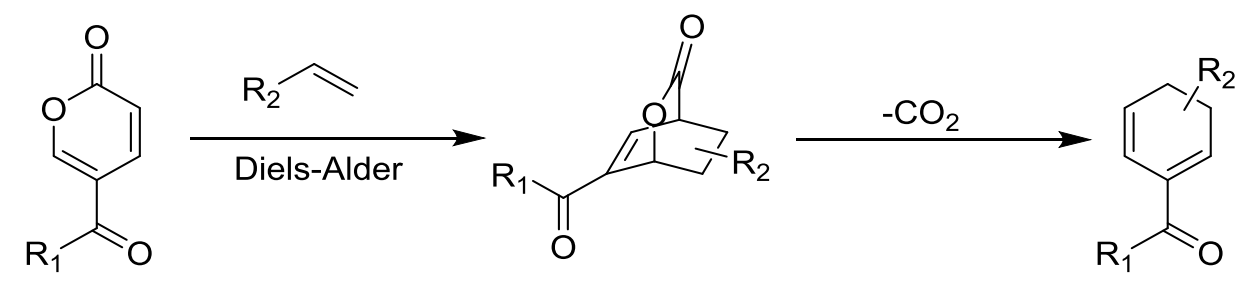

Scheme 14: Diels-Alder conversion of 2-pyrones followed by decarboxylation to dihydrobenzenes ${ }^{111}$

Despite the low yield of the decarboxylation presented by Pfenning et al. this reaction is particularly interesting because 2-pyrone is a biobased molecule coming from coumalic acid. ${ }^{118}$ Moreover the production of carbon dioxide is interesting due to the non-toxicity of this gas. 


\section{4) Amine Decarbonation}

The amine carbonate is usually obtained by the reaction of carbon dioxide with amine. This reaction takes place at room temperature. A white solid usually characterizes the product of this reaction. The white deposit often observed on the side of amine bottle is typically the product from $\mathrm{CO}_{2}$ and amine reaction. It can also be observed in epoxy coatings, depicted as amine blush. ${ }^{119}$ In 2004, da Silva et al. studied the mechanism of the amine carbonation. They determined a single-step (scheme 15), third order reaction mechanism, where water could be the base. ${ }^{120}$

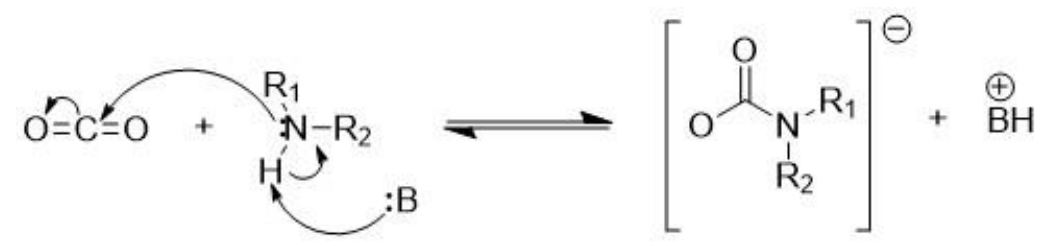

Scheme 15 : Amine carbonation mechanism ${ }^{111}$

The interest of the amine decarbonation comes from the release of carbon dioxide under thermal conditions. Some researches were carried out in order to determine the switchable aspect of the $\mathrm{CO}_{2}$ in order to release $\mathrm{CO}_{2}$ and amine, ${ }^{121-126}$ available to create networks, for example. Ren et al. ${ }^{127}$ presented the synthesis of epoxy foams using decarbonation of amine as CBA (figure 8). The blowing reaction took place at $130{ }^{\circ} \mathrm{C}$ and led to foams with density around $0.30 \mathrm{~g} / \mathrm{m}^{3}$. The advantage of this work was the synthesis of epoxy foam under mild conditions. Both primary and secondary amines could be carbonated, then both decarbonated as same temperature, as it was demonstrated by Ren et al.. ${ }^{127}$ However, Da et al. presented the synthesis of a PU foam using both primary and secondary carbonated amines. ${ }^{128}$ They notably discussed the effect of the steric hindrance on the secondary amine and reported that primary amine was more difficult to decarbonate at $100^{\circ} \mathrm{C}$. The carbon dioxide is an interesting gas to produce since it is non-toxic and non-flammable. However, the carbonation of amine is not so easy since it requires bubbling of $\mathrm{CO}_{2}$ in the amine. The difficult part remains the determination of the carbonation yield and then the gas amount induced in the foam. The amine formed after the decarbonation is still able to react, so it could lead to a wide range of reactions such as epoxy-amine, aza-Michael or aminolysis of cyclic carbonate.

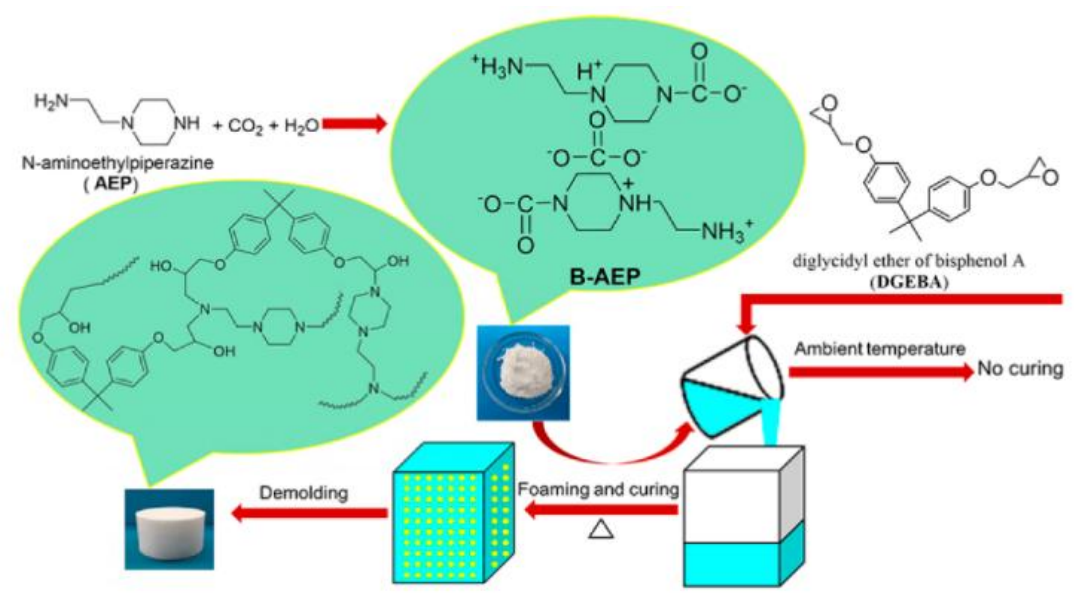

Figure 8: Process for foam preparation 121 
5) Cyclocarbonate decarbonation

In 2003, Clements published a review about cyclic alkylene carbonates ${ }^{129}$ which presented an original way to produce carbon dioxide. Indeed, cyclocarbonates are known to undergo ring-opening polymerization with amine and a catalyst. Nevertheless, the $\mathrm{CO}_{2}$ moiety is usually not removed. Clements presented several works proving that the reaction between cyclocarbonate and aromatic nucleophile could lead to $\mathrm{CO}_{2}$ production after the nucleophile attack. Additionally, King described a process using aniline as nucleophile, the range of temperature required to undergo the reaction was typically from $100^{\circ} \mathrm{C}$ to $150^{\circ} \mathrm{C} .{ }^{130}$ Two products were obtained owing to the mechanism given by Clements (scheme 16), the ratio between the two molecules was 50/50.
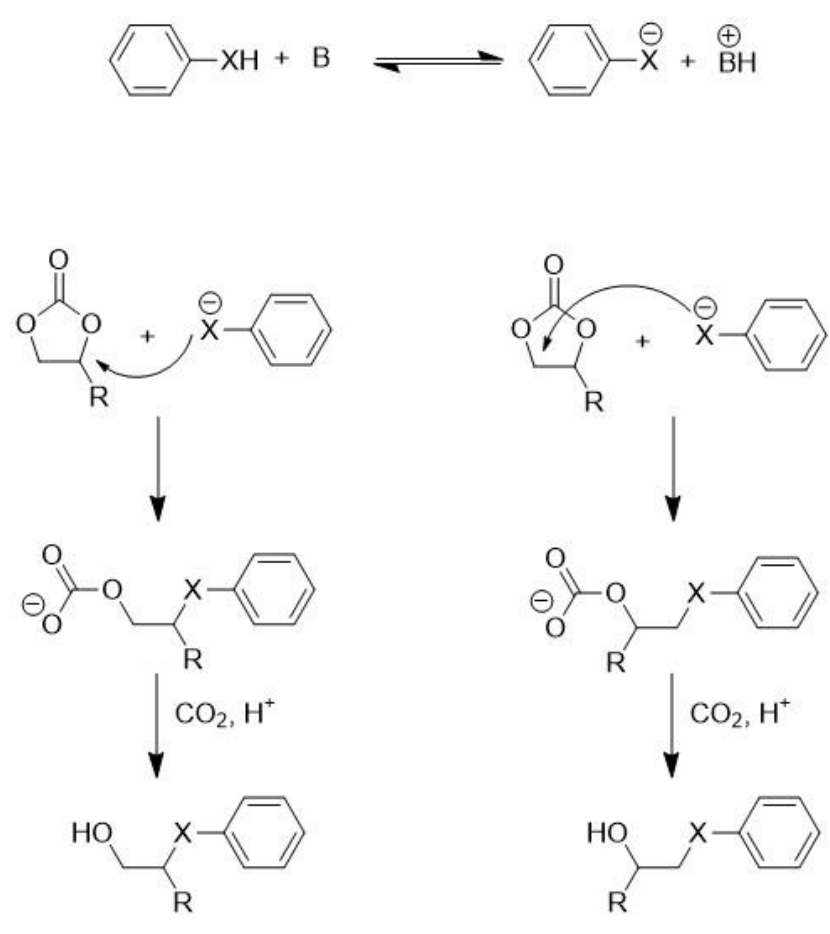

Scheme 16: Cyclocarbonate decarbonation using nucleophile124

6) N-Carboxyanhydride (NCA)

NCAs are functional monomers generally used in ring opening polymerization (ROP) in order to synthesize polypeptides especially for drug delivery of health applications. Deming et al. carried out a lot of works on NCA ${ }^{131,132}$ as well as Lecommandoux et al. ${ }^{133,134}$. During the ROP, an amine reacts with NCA, leading to formation of an amino-acid unit, with reactive amine group to propagate ROP and releasing carbon dioxide as by-product. Hence, NCA could be promising CBAs which releases carbon dioxide at room temperature (Scheme 17).<smiles></smiles>

Scheme 17: Ring Opening Polymerization of NCAs initiated with a primary amine

Several studies have been carried out using the ROP between $0^{\circ} \mathrm{C}$ and room temperature, where the ROP of NCA is usually initiated with a primary amine. For example, Murphy et al. presented the ROP 
initiated with allylamine ${ }^{135}$. Sulistio et al. presented the ROP for dendrimer synthesis. ${ }^{136}$ NCAs seem really interesting, nevertheless they present an important drawback. NCAs are water sensible, indeed water is a nucleophile that could initiate their ROP. Thus, the previous researches presented synthesis under inert atmosphere. Moreover the price of these compounds is important due to their multi-step synthesis requiring hazardous compounds (e.g. triphosgene) and purification steps. NCAs could be used in order to blow PHUs or polyepoxides. Hence, for example a NCA moiety could be grafted on the monomer and during the reaction the produced amine can be used as hardener. Moreover, the amine could simultaneously react with the blowing agent and the matrix e.g cyclocarbonate or epoxide, respectively.

\section{7) Wolff-Kishner reaction}

The Wolff-Kishner reduction (WK) is a well know organic reaction discovered in the early 1910s. ${ }^{137}$ This reaction is used to convert a carbonyl function into methylene group (scheme 18). The first step of the WK reaction is the hydrazine condensation on a ketone or an aldehyde in order to generate hydrazone. Then, the condensation is followed by a basic treatment which yields the corresponding alkane and leads to the release of nitrogen.

(A) Wolff-Kishner reduction

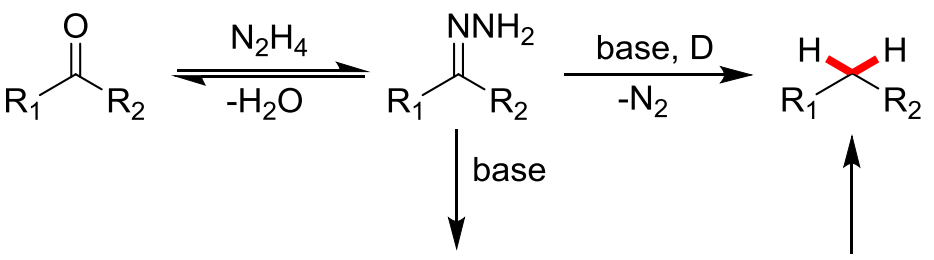

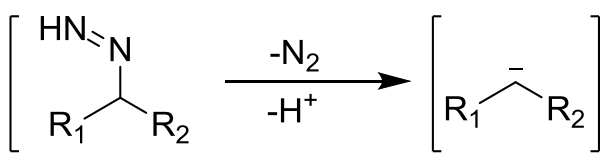

(B) Li's modification

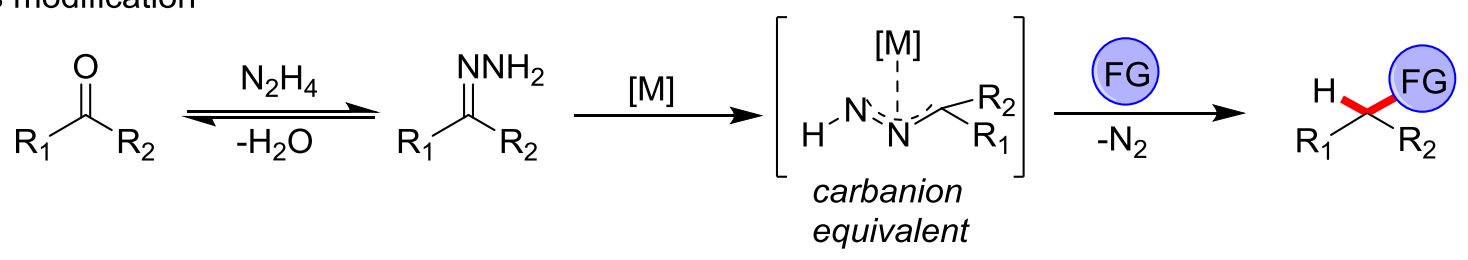

Scheme 18: Wolff-Kishner reduction reaction and Li's modification mechanism

The interest of this reaction lies on the release of nitrogen. Different groups can be grafted to the ketone or aldehyde (various $R_{1}$ and $R_{2}$ - scheme 18) using WK reaction. ${ }^{138}$ Nevertheless, the reaction needs hydrazine, a highly harmful chemical, in order to obtain hydrazone. Moreover, the use of a strong base is required to deprotonate hydrazine. Despite the use of harmful precursors, this reaction is interesting because it can be carried out under mild conditions. Moreover Wang et $a l^{138}$ have carried out this reaction by photochemistry. Hence, the adduct could be interestingly used as CBA. Nevertheless, the toxicity of the precursors should limit the use of this reaction for blowing foams. The WK reaction could possibly be used for PUs, PS or polyesters. 
8) Conclusion

Table 3: properties of original CBAs

\begin{tabular}{|c|c|c|c|}
\hline CBA & Temperature $\left({ }^{\circ} \mathrm{C}\right)$ & Gas & Polymer \\
\hline Metal/Acid & RT & $\mathrm{H}_{2}$ & - \\
\hline Siloxane & 50 & $\mathrm{H}_{2}$ & Epoxy $^{102}$ \\
\hline PMHS & $\mathrm{RT}-50$ & $\mathrm{H}_{2}$ & PHUs $^{103}$ \\
\hline Retro Diels-Alder & $\mathrm{RT}$ & $\mathrm{N}_{2}$ & - \\
\hline $\begin{array}{c}\text { Amine } \\
\text { decarbonation }\end{array}$ & $90-130$ & $\mathrm{CO}_{2}$ & $\mathrm{PU}^{128}, \mathrm{Epoxy}^{127}$ \\
\hline NCA & $\mathrm{RT}$ & $\mathrm{CO}_{2}$ & - \\
\hline Wolf-Kischner & $\mathrm{RT}$ & $\mathrm{N}_{2}$ & - \\
\hline
\end{tabular}

Several precursors and reactions were presented as various new possibilities to blow foams in this part. The list is not exhaustive but almost all the presented precursors could act as interesting CBAs for blowing foams. Deeper studied are now needed to confirm interest and make some of these precursors new promising CBAs.

\section{Conclusion}

The vast range of available blowing agent provides a wide choice of molecules in order to blow polymer foams. Despite the need of specific equipment, physical blowing agents (PBAs) are widely used. In fact, CBAs are still less used than PBAs because of their relatively high price and their lower gas yield. Nevertheless, PBAs are generally flammable or lead to environmental concerns. Thus, CBAs are the main answer to replace them. The wide range of CBAs allows an adaptability to almost all polymer foams. For most of them, their discovery and development took place during the 60 's or 80 's. Most of them were presented in this review because of their industrial interest. Therefore, they were perfectly adapted to the issues of the society 60 years ago. The most significant example is the replacement of isocyanates. They are still widely used as CBA in PU foams but classified as toxic, and the regulation will soon ban their use. Hence, increasing attention is paid to the numerous works carried out to replace them and find a self-blowing PU foam at room temperature. These works mainly concern the pathways to obtain a polymer at room temperature and use commercial CBA in order to blow the foams. In order to find a new CBA adapted to our century, few perspectives are explored. Despite the great interest of present CBA, they always lead to open-cell structure due to the gas type produced. In order to avoid open-cell structure, additives such as nucleating agent can be added to the foam formulation.

The present review showed the interest of ICBAs as extreme either low and high temperature blowing agents, producing mainly carbon dioxide or hydrogen. They are used for various polymer foams, however the production of solid residues is an important drawback since specific migration can occur in the final material leading to health concerns. 
The OCBAs showed complementary characteristic, the main gas produced is nitrogen and the usual foaming reaction takes place under high temperature. These CBAs are interesting due to their wide range of use. Nevertheless some of the compound are unstable (even explosive for some), so it is more complicated to use them. Moreover some toxicity concerns can be linked to these kinds of CBAs. Thus the last part presented alternatives to these CBAs. Indeed, this last part was focused on interesting chemical reactions that release gas by-products and that could well be promising as foaming process. Some of these new CBAs could be incorporated into the polymer matrix, avoiding the detrimental presence of residues as it is generally the case for OCBAs. This point is important but some of the presented perspective CBAs use toxic compounds or release hydrogen, which implies hazardous concern. These promising foaming reactions deserved to be presented but are not a fully developed answer to the current issues and deeper studies are needed to evaluate the potential of some of these CBAs. In the future the foaming industry will face changes. Thus the review tried to show some potential solutions, in order to anticipate these changes. Generally, the choice of CBA is complex since it should take into account the different required properties of the porous final material (e.g. porosity, cell size, cell type, etc.) prior the reaction. Hence, reaction parameters should be known in order to blow the material correctly. Thus, the temperature of decomposition (gas production) should be coherent with the melting point of the polymer in order to obtain a viscosity allowing the homogeneous dispersion of the CBA and its decomposition. If the polymer is not already synthesized, the blowing temperature should be coherent with the temperature required to synthesize the polymer. Then the compatibility between the CBA and the polymer and the potential adverse side reaction due to foaming (e.g. urea formation during isocyanate and water reaction) should be studied. Thus, to choose a proper CBA or an ideal CBA/polymer system there are a lot of parameters to determine and each polymer/reaction/final material requires different conditions.

1. Gama, N. V; Ferreira, A.; Barros-Timmons, A. Polyurethane foams: Past, present, and future. Materials (Basel). 2018, 11, 1841-1876.

2. Weber, H.; De Grave, I.; Röhrl, E.; Altstädt, V. In Ullman's Ecyclopedia of Industrial Chemistry.; Wiley-VCH, 2016; pp 1.

3. Polymer Foam Market Size, Share \& Trends Analysis Report By Type (Polyurethane, Polystyrene, Polyolefin, Melamine, Phenolic, PVC), By Application, By Region, And Segment Forecasts, 2020 - 2027. journal (accessed June 9, 2020).

4. $\quad$ Ellen, P.; Myrin E., S. Mapping the plastics system and its sustainability challenges; 2018.

5. Polyurethane Production, Pricing and Market Demand. https://www.plasticsinsight.com/resin-intelligence/resin-prices/polyurethane/ (accessed April 1, 2020).

6. Bayer, O. Angew. Chemie A 1947, 59, 257.

7. Weber, H.; De Grave, I.; Röhrl, E. In Ulmann's Encyclopedia of Industrial Chemistry; Wiley-VCH, 2012; Vol. 15, pp 539.

8. Eaves, D. Handbook Polymer of foams; Rapra Technology Limited Shawbury, 2004.

9. Wypych, G. Handbook of Foaming and Blowing Agents; First Edit.; ChemTec Publishing, 2017; 
Vol. 1.

10. Ionescu, M. Chemistry and Technology of Polyols for Polyurethanes, 2nd Edition Chemistry and Technology of Polyols for Polyurethanes, 2nd Edition; 2016; Vol. 2.

11. Lober, F. Angew. Chemie 1952, 64, 65.

12. Elsner, C. Natural Foam Blowing Agents Sustainable Ozone-and Climate-Friendly Alternatives to HCFCs Proklima International; Volkmar, H.; Linda, E.; Igor, C.; Jürgen, U., Eds.; Proklima I.; Deutsche Gesellschaft für Internationale Zusammenarbeit, 2012.

13. The Montreal Protocol on Substances that Deplete the Ozone Layer. https://web.archive.org/web/20130602153542

/http://ozone.unep.org/new_site/en/montreal_protocol.php (accessed April 2, 2020).

14. Ciconkov, R. Int. J. Refrig. 2018, 86, 441.

15. Greenpeace HFOs: the new generation of F-gases. https://www.greenpeace.org/archiveinternational/Global/international/documents/climate/HFOs-the-new-generation-of-fgases.pdf.

16. Szczurek, A.; Fierro, V.; Pizzi, A.; Stauber, M.; Celzard, A. Ibdustrial Crop. Prod. 2014, 54, 40.

17. Grignard, B.; Thomassin, J. M.; Gennen, S.; Poussard, L.; Bonnaud, L.; Raquez, J. M.; Dubois, P.; Tran, M. P.; Park, C. B.; Jerome, C.; Detrembleur, C. Green Chem. 2016, 18, 2206.

18. Pilon, L.; Fedorov, A. G.; Viskanta, R. J. Cell. Plast. 2000, 36, 451.

19. Quinn, S. Plast. Addit. Compd. 2001, 3, 16.

20. Pontiff, T. Foaming agents for foam extrusion; Lee, S.-T.; Park, C. B., Eds.; 2nd Editio.; CRC Press, 2014.

21. Wang, L.; Wu, Y. K.; Ai, F. F.; Fan, J.; Xia, Z. P.; Liu, Y. Polymers (Basel). 2018, 10, 1310.

22. Hussein, M. S.; Leng, T. P.; Rahmat, A. R.; Zainuddin, F.; Keat, Y. C.; Suppiah, K.; Alsagayar, Z. S. Mater. Today Proc. 2019, 16, 1622.

23. Ji, Y.; Luo, H.; Shi, M.; Yang, Z.; Gong, W.; Tan, H. J. Polym. Eng. 2019, 39, 117.

24. Najib, N. N.; Ariff, Z. M.; Manan, N. A.; Baker, A. A.; Sipaut, C. S. J. Phys. Sci. 2009, 20, 13.

25. Heck, R. L. I.; Peascoe, W. J. In Encyclopedia of Polymer Science and Technology; Wiley, Ed.; 2011; pp 1.

26. Uy Lan, D. N.; Fauzi, M. S.; Viet, C. X.; Raps, D.; Altstädt, V. J. Cell. Plast. 2020, 56, 105.

27. Karlsson, K.; Larsson, E.; Lorén, N.; Stading, M.; Rigdahl, M. J. Polym. Environ. 2019, 27, 1167.

28. Altuna, F. I.; Ruseckaite, R. A.; Stefani, P. M. ACS Sustain. Chem. Eng. 2015, 3, 1406.

29. Julien, J. M.; Quantin, J. C.; Bénézet, J. C.; Bergeret, A.; Lacrampe, M. F.; Krawczak, P. Eur. Polym. J. 2015, 67, 40.

30. Xi, X.; Pizzi, A.; Gerardin, C.; Du, G. J. Renew. Mater. 2019, 7, 301.

31. Allioux, F. M.; Merhebi, S.; Tang, J.; Idrus-Saidi, S. A.; Abbasi, R.; Saborio, M. G.; Ghasemian, M. B.; Han, J.; Namivandi-Zangeneh, R.; O'Mullane, A. P.; Koshy, P.; Daiyan, R.; Amal, R.; Boyer, C.; Kalantar-Zadeh, K. Adv. Funct. Mater. 2020, 30, 1.

32. Asthana, H. Foamed Polycarbonate articles with improved and methoids of making and uses thereof 2018.

33. Seguin, J.; Cavalier, K. Functionalized Particulate Bicarbonate as Blowing Agent, Foamable polymer compositio, containing it, and it use in manufacturing a thermoplastic foamed 
polymer. 2019.

34. Wolschleger, L. M.; Mabilia, J. Heat Expandable Foam 2018.

35. Niessner, N.; Abboud, M.; Chung, A. Lightweight styrene polymer compositions 2017.

36. Mazzon, E.; Guigues, P.; Habas, J.-P. Epoxy foams derived from biosourced reactive formulations 2016.

37. Zerafati, S.; Stabler, S. M. Foamed Polyvinylidene Fluorine Structure 2010.

38. Coleman, E. A. 21 Plastics Additives; Second Edi.; Elsevier Inc., 2017.

39. Wu, F.; Harper, B. J.; Harper, S. L. Environ. Toxicol. Chem. 2019, 38, 591.

40. Oveisi, H.; Geramipour, T. Geophys. Res. Lett. 2019.

41. Paswan, D.; Mistry, D.; Sahoo, K. L.; Srivastava, V. C. J. Mater. Eng. Perform. 2013, 22, 2201.

42. Chem. Eng. News Arch. 1959, 37, 38.

43. Wade, R. Ind. Eng. Chem. 1960, 52, 20.

44. Wade, R. C.; Letendre, C. J. Cell. Plast. 1980, 16, 32.

45. Kass, R. Cellular polyurethanes Prepared Utilizing Sodium Borohydride as a Blowing Agent 1967.

46. Joslyn, W. G. Foaming unsaturated polyester resins 1974.

47. Feng, J.; Zhang, R.; Gong, L.; Li, Y.; Cao, W.; Cheng, X. Mater. Des. 2014, 65, 529.

48. Petlitckaia, S.; Poulesquen, A. Ceram. Int. 2019, 45, 1322.

49. Rao, P. R.; Muralidharan, K.; Momayez, M.; Runge, K. A.; Loy, D. A. Ceram. Int. 2020, 46, 10431.

50. Hartmann, J.; Fiegl, T.; Körner, C. Appl. Phys. A Mater. Sci. Process. 2014, 115, 651.

51. Zhao, W.; He, S. yuan; Zhang, Y.; Zhang, C.; Tang, G. yi; Dai, G. Mater. Lett. 2020, 266, 127482.

52. Koike, R.; Matsumoto, T.; Kakinuma, Y.; Aoyama, T.; Oda, Y.; Kuriya, T.; Kondo, M. Procedia Manuf. 2018, 18, 68.

53. Chao, C. H.; Jen, T. C. Appl. Mech. Mater. 2013, 302, 151.

54. Leckey, J. H.; Nulf, L. E.; Kirkpatrick, J. R. Langmuir 1996, 12, 6361.

55. Tegel, M.; Schöne, S.; Kieback, B.; Röntzsch, L. Int. J. Hydrogen Energy 2017, 42, 2167.

56. Sadik, T.; Pillon, C.; Carrot, C.; Reglero Ruiz, J. A. Thermochim. Acta 2018, 659, 74.

57. Barrère, M.; Landfester, K. Macromolecules 2003, 36, 5119.

58. Wang, B.; Wang, X.; Chen, K. Vegetable oil-based cartilage bionic cushioning and shockabsorbing material, and preparation method and use thereof 2017.

59. Wai, W.; Zheng, C.; Wei, Y. A polyurethane foam and a polyurethane composite comprising the same 2017.

60. Masahitko, T. Polyurethane forming composition and flexible polyurethane foam 2017.

61. Yang, Z.; Peng, H.; Wang, W.; Liu, T. J. Appl. Polym. Sci. 2010, 116, 2658.

62. Karol, M. H.; Dean, J. H. Crit. Rev. Toxicol. 1986, 16, 349.

63. Karol, M. H.; Kramarik, J. A. Toxicol. Lett. 1996, 89, 139.

64. Varma, D. R.; Guest, I. J. Toxicol. Environ. Health 1993, 40, 513. 
65. Agency, E. C. ECHA Scientific report for evaluation of limit values for diisocyanates at the workplace; 2019.

66. Furtwengler, P.; Perrin, R.; Redl, A.; Avérous, L. Eur. Polym. J. 2017, 97, 319.

67. Furtwengler, P.; Avérous, L. Polym. Chem. 2018, 9, 4258.

68. Gwon, J. G.; Kim, S. K.; Kim, J. H. J. Porous Mater. 2016, 23, 465.

69. Sun, G.; Wang, W.; Wang, L.; Yang, Z.; Liu, L.; Wang, J.; Ma, N.; Wei, H.; Han, S. J. Appl. Polym. Sci. 2017, 134, 2.

70. Kmetty, Á.; Litauszki, K. Appl. Sci. 2018, 8, 1.

71. Michałowski, S.; Prociak, A.; Zajchowski, S.; Tomaszewska, J.; Mirowski, J. Polym. Test. 2017, 64, 229.

72. Zauzi, N. S. A.; Ariff, Z. M.; Khimi, S. R. Mater. Today Proc. 2019, 17, 1001.

73. Frick, K.; Krüger, C.; Cil, E. Thermoplastic formulation with improved adhesion 2018.

74. Zauner, C.; Bettermann, M. Flexible foam with improved insulation properties 2018.

75. Boonprasertpoh, A.; Pentrakoon, D.; Junkasem, J. Cell. Polym. 2020, 39, 31.

76. Kao, C.-H. Plant fiber foam board and method making the same 2019.

77. Lai, Z.; Clark, M.; Wallenta, K.; Nuila Coating Composition 2017.

78. Zhang, X.; Qi, C. Foaming composition 2017.

79. Oikawa, E.; Tamura, S.; Arai, Y.; Toshiki, A. J. Appl. Polym. Sci. 1995, 58, 1205.

80. Lober, F.; Bögemann, M. Hydrazide of Organic Sulfonic Acid as Blowing Agent in Plastics 1953.

81. Schoene, D. L. Oxybisphenylsulfonhydrazide 1951.

82. Cai, L. F.; Huang, X. B.; Rong, M. Z.; Ruan, W. H.; Zhang, M. Q. Macromol. Chem. Phys. 2006, 207, 2093.

83. Hunter, B. A.; Schoene, D. L. Ind. Eng. Chem. 1952, 44, 119.

84. Clayton, T. A. Method of Making Gas-Expanded Organic Plastics 1953.

85. Cai, L. F.; Huang, X. B.; Rong, M. Z.; Ruan, W. H.; Zhang, M. Q. Polymer (Guildf). 2006, 47, 7043.

86. Jeong, J.; Kim, T.; Cho, W. J.; Chung, I. Polym. Int. 2013, 62, 1094.

87. Jeong, J.; Yang, J.; Ha, C. S.; Cho, W. J.; Chung, I. Polym. Bull. 2012, 68, 1227.

88. Jeong, J.; Kim, G.; Lee, S.; Kim, G. W.; Kim, D. H.; Chung, I. Macromol. Res. 2017, 25, 128.

89. Mori, K.; Nakamura, Y.; Tamura, K. J. Appl. Polym. Sci. 1978, 22, 2685.

90. Hunter, B. A.; Root, F. B.; Morrisey, G. J. Cell. Plast. 1967, 3, 268.

91. Stepek, J.; Doust, H. Additives for Plastics; 1983.

92. Ahn, D.-U.; Jein, J.-B.; Kim, S.-J. Microcellular foamed nanocomposite and preparation method thereof 2016.

93. Harbel, J.; Krause, W. Process for producing an open cell thermoplastic foam 2017.

94. Jiang, P.; Sahoune, A.; Dekmezian, A. Foamable thermoplastic reactor blends and foam article therefrom 2012.

95. Dixon, M.; Small, C.; Brown, P. Thermoplastic polymers foamed with a semicarbazide 2016. 
96. Yi, K. S.; Lim, S. H. Foam composition, flexible thermoelectric device, flexible conductive laminate and production method thereof 2019.

97. Moore, L. D.; Randall, J. J. Method of Foaming Thermospastic Polymeric Materials using Hydrocarbyltetrazoles as the Foaming Agent 1969.

98. Kiselev, V. G.; Gritsan, N. P. J. Phys. Chem. A 2009, 113, 3677.

99. Birk, J. P.; Walters, D. L. J. Chem. Educ. 1993, 70, 587.

100. Zheng, L.; Zhang, X.; Wang, Y.; Liu, F.; Peng, J.; Zhao, X.; Yang, H.; Ma, L.; Wang, B.; Chang, C.; Wei, H. Biomacromolecules 2018, 19, 3874.

101. Modvig, A.; Andersen, T. L.; Taaning, R. H.; Lindhardt, A. T.; Skrydstrup, T. J. Org. Chem. 2014, $79,5861$.

102. Stefani, P. M.; Barchi, A. T.; Sabugal, J.; Vazquez, A. J. Appl. Polym. Sci. 2003, 90, 2992.

103. Cornille, A.; Dworakowska, S.; Bogdal, D.; Boutevin, B.; Caillol, S. Eur. Polym. J. 2015, 66, 129.

104. Cornille, A.; Guillet, C.; Benyahya, S.; Negrell, C.; Boutevin, B.; Caillol, S. Eur. Polym. J. 2016, 84, 873.

105. Duval, A.; Couture, G.; Caillol, S.; Avérous, L. ACS Sustain. Chem. Eng. 2017, 5, 1199.

106. Zheng, K.; Tian, Y.; Fan, M.; Zhang, J.; Cheng, J. J. Appl. Polym. Sci. 2018, 135, 1.

107. Tremblay-Parrado, K. K.; Avérous, L. ChemSusChem 2020, 13, 238.

108. Jung, S.; Liu, J. T.; Hong, S. H.; Arunbabu, D.; Noh, S. M.; Oh, J. K. Polymer (Guildf). 2017, 109, 58.

109. Dobbins, D. J.; Scheutz, G. M.; Sun, H.; Crouse, C. A.; Sumerlin, B. S. J. Polym. Sci. Part A Polym. Chem. 2019, 193.

110. Hayashi, S.; Narita, A.; Wasano, T.; Tachibana, Y.; Kasuya, K. ichi Eur. Polym. J. 2019, 121, 109333.

111. Rieber, N.; Alberts, J.; Lipsky, J. A.; Lemal, D. M. J. Am. Chem. Soc. 1969, 91, 5668.

112. Törk, L.; Jiménez-Osés, G.; Doubleday, C.; Liu, F.; Houk, K. N. J. Am. Chem. Soc. 2015, 137, 4749.

113. Pipkorn, R.; Waldeck, W.; Didinger, B.; Koch, M.; Mueller, G.; Wiessler, M.; Braun, K. J. Pept. Sci. 2009, 15, 235.

114. Wiessler, M.; Waldeck, W.; Kliem, C.; Pipkorn, R.; Braun, K. Int. J. Med. Sci. 2010, 7, 19.

115. Alder, K.; Ferdinand, H. F. Berichte der Dtsch. Chem. Gesellschaft (A B Ser. 1937, 70, 1354.

116. Reed, J. A.; Schilling, C. L.; Tarvin, R. F.; Rettig, T. A.; Stille, J. K. J. Org. Chem. 1969, 34, 2188.

117. Pfennig, T.; Chemburkar, A.; Johnson, R. L.; Ryan, M. J.; Rossini, A. J.; Neurock, M.; Shanks, B. H. ACS Catal. 2018, 8, 2450.

118. Lee, J. J.; Kraus, G. A. Green Chem. 2014, 16, 2111.

119. Blain, M.; Jean-Gérard, L.; Benazet, D.; Boutevin, B.; Andrioletti, B.; Caillol, S. Macromol. Mater. Eng. 2016, 301, 682.

120. Da Silva, E. F.; Svendsen, H. F. Ind. Eng. Chem. Res. 2004, 43, 3413.

121. Pinaud, J.; Kowal, E.; Cunningham, M.; Jessop, P. ACS Macro Lett. 2012, 1, 1103.

122. Lin, S.; Theato, P. Macromol. Rapid Commun. 2013, 34, 1118.

123. Lei, L.; Zhang, Q.; Shi, S.; Zhu, S. ACS Macro Lett. 2016, 5, 828. 
124. Liu, Y.; Jessop, P. G.; Cunningham, M.; Eckert, C. A.; Liotta, C. L. Science (80-. ). 2006, 313, 958.

125. Han, D.; Tong, X.; Boissière, O.; Zhao, Y. ACS Macro Lett. 2012, 1, 57.

126. George, M.; Weiss, R. G. Langmuir 2002, 18, 7124.

127. Ren, Q.; Zhu, S. ACS Macro Lett. 2015, 4, 693.

128. Da, X.; Liu, C.; Long, Y.; Xie, X. J. Appl. Polym. Sci. 2020, 137.

129. Clements, J. H. Ind. Eng. Chem. Res. 2003, 42, 663.

130. King, C. C. Alkylation of Aromatic Hydrocarbons 1957.

131. Yakovlev, I.; Deming, T. J. ACS Macro Lett. 2014, 3, 378.

132. Bansal, V.; Sharma, P. K.; Sharma, N.; Pal, O. P.; Malviya, R. Biol. Res. 2011, 5, 28.

133. Le Fer, G.; Portes, D.; Goudounet, G.; Guigner, J. M.; Garanger, E.; Lecommandoux, S. Org. Biomol. Chem. 2017, 15, 10095.

134. Agut, W.; Agnaou, R.; Lecommandoux, S.; Taton, D. Macromol. Rapid Commun. 2008, 29, 1147.

135. Murphy, R. D.; Bobbi, E.; de Oliveira, F. C. S.; Cryan, S. A.; Heise, A. J. Polym. Sci. Part A Polym. Chem. 2019, 57, 1209.

136. Sulistio, A.; Lowenthal, J.; Blencowe, A.; Bongiovanni, M. N.; Ong, L.; Gras, S. L.; Zhang, X.; Qiao, G. G. Biomacromolecules 2011, 12, 3469.

137. Wolff, L. Liebigs Ann. 1898, 394, 86.

138. Ko, B.; Wang, S.; Cheng, B.; Srs, M. J. Am. Chem. Soc. 2020. 